\title{
Assessment of Barrier Island Morphological Change in Northern Alaska
}

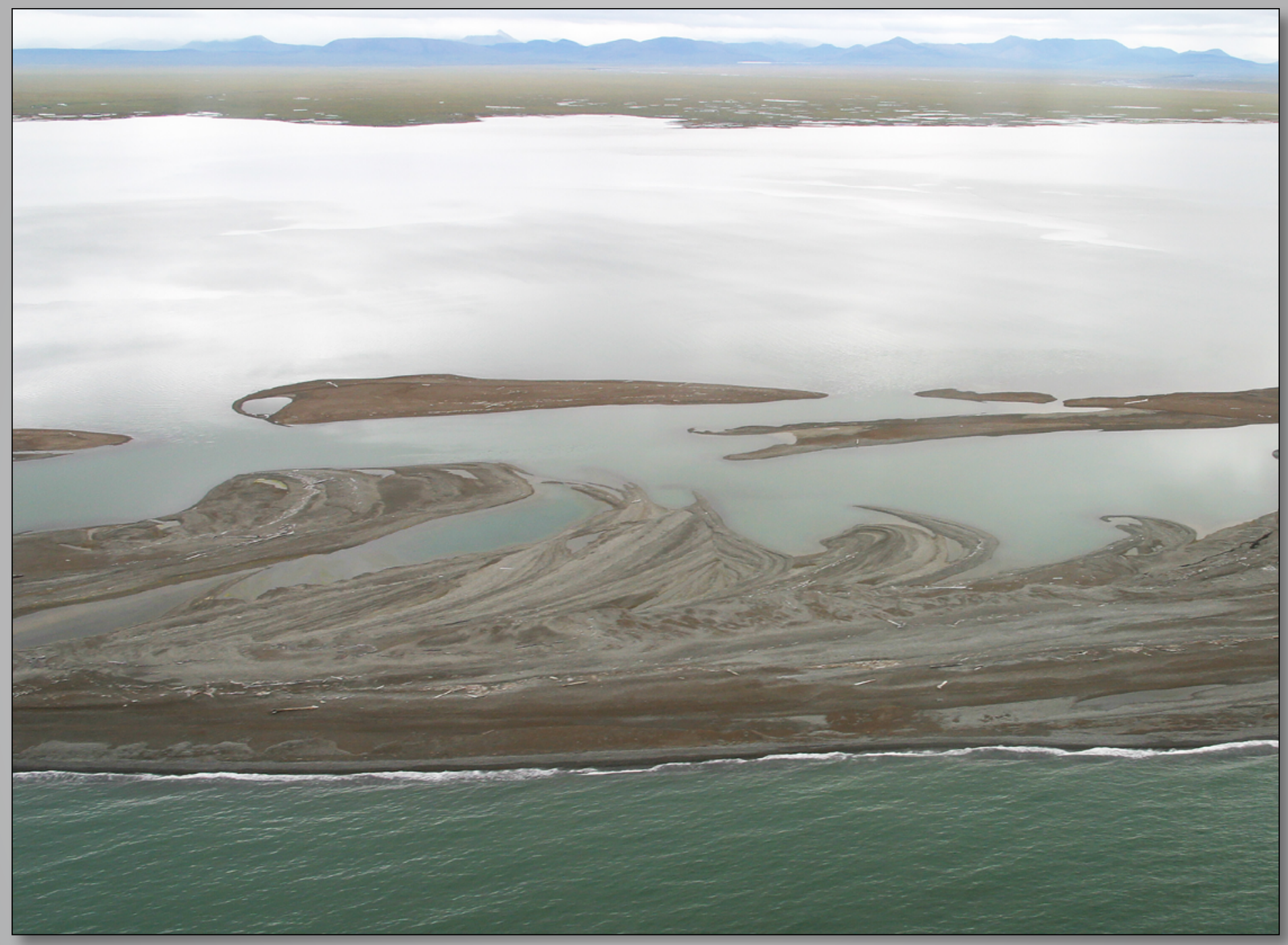

Open-File Report 2021-1074 
Cover. Photograph of barrier islands near the western terminus of Icy Reef located on the Beaufort Sea coast of Alaska, looking south. Egaksrak Lagoon separates the islands from the low-lying mainland coast of the Arctic National Wildlife Refuge and the Brooks Range in the background. Photo taken by Bruce Richmond/Ann Gibbs, USGS.

Gibbs, A.E., and Richmond, B.M., 2009, Oblique aerial photography of the Arctic coast of Alaska, Nulavik to Demarcation Point, August 7-10, 2006: U.S. Geological Survey Data Series 436, 6 p., 4 databases, http://pubs.usgs.gov/ds/436/. 


\section{Assessment of Barrier Island Morphological Change in Northern Alaska}

By Anna I. Hamilton, Ann E. Gibbs, Li H. Erikson, and Anita C. Engelstad

Open-File Report 2021-1074 


\section{U.S. Geological Survey, Reston, Virginia: 2021}

For more information on the USGS — the Federal source for science about the Earth, its natural and living resources, natural hazards, and the environment-visit https://www.usgs.gov/ or call 1-888-ASK-USGS (1-888-275-8747).

For an overview of USGS information products, including maps, imagery, and publications, visit https://store.usgs.gov.

Any use of trade, firm, or product names is for descriptive purposes only and does not imply endorsement by the U.S. Government.

Although this information product, for the most part, is in the public domain, it also may contain copyrighted materials as noted in the text. Permission to reproduce copyrighted items must be secured from the copyright owner.

Suggested citation:

Hamilton, A.I., Gibbs, A.E., Erikson, L.H., and Engelstad, A.C., 2021, Assessment of barrier island morphological change in northern Alaska: U.S. Geological Survey Open-File Report 2021-1074, 28 p., https://doi.org/10.3133/ofr20211074.

Associated data for this publication:

Hamilton, A.I., Gibbs, A.E., Erikson, L.H., and Engelstad, A.C., 2021, Historical shorelines and morphological metrics for barrier islands and spits along the north coast of Alaska between Cape Beaufort and the U.S.-Canadian border, 1947 to 2019: U.S. Geological Survey data release, https://doi.org/10.5066/P90E01H7. 


\section{Acknowledgments}

Supervision, suggestions, and knowledge input from Aart Kroon at the University of Copenhagen greatly improved the content of this report.

\section{Contents}

Acknowledgments ...................................................................................................................ii

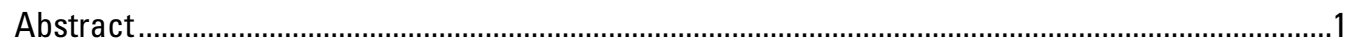

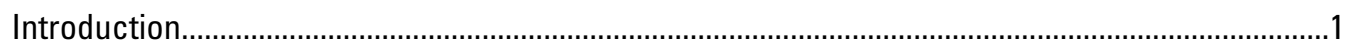

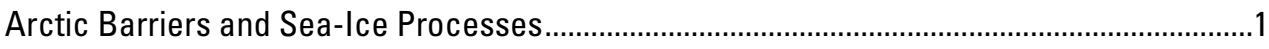

Impact of Temperature Changes in the Arctic ....................................................................

Atmospheric Oscillations and their Influence in the Arctic ..................................................

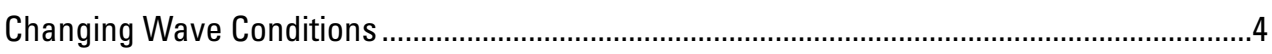

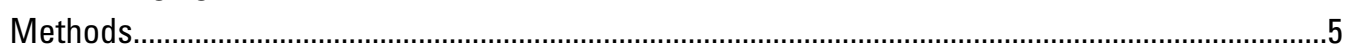

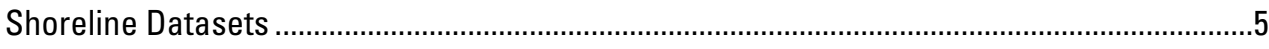

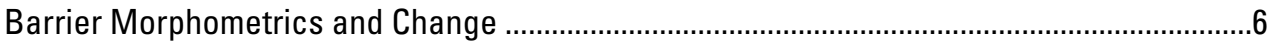

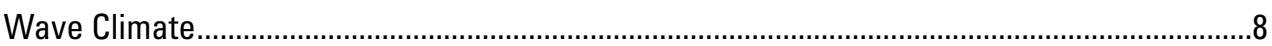

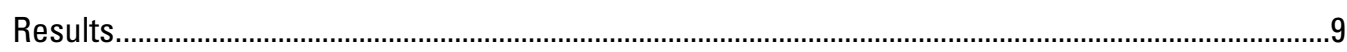

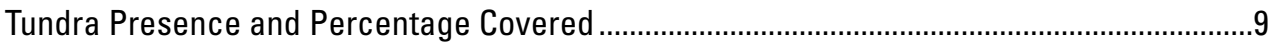

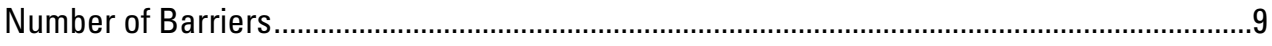

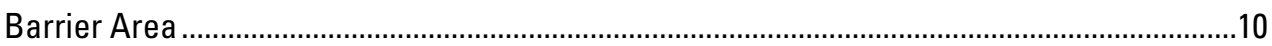

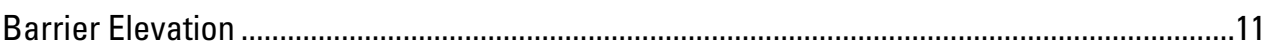

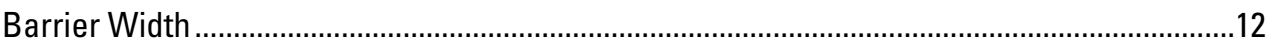

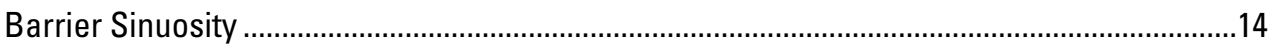

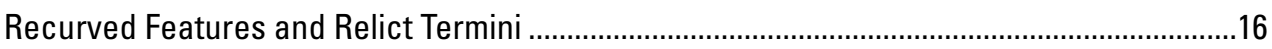

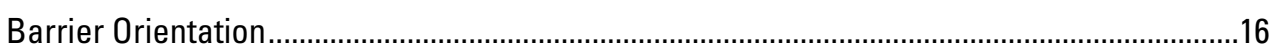

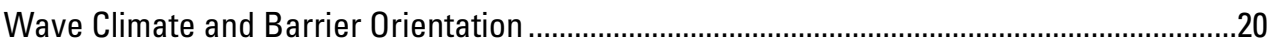

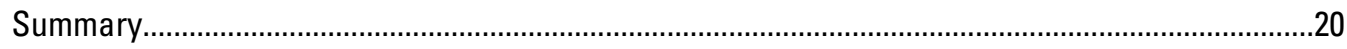

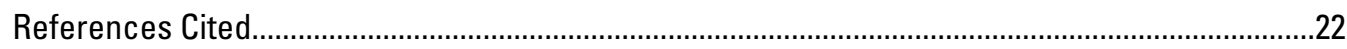

Appendix 1. Feature Type and Name or Geographical Area of Barrier Island Chains....................25

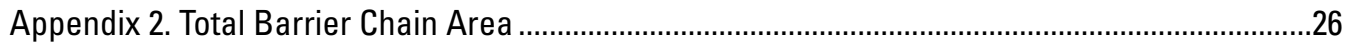

Appendix 3. Wave Roses for Each Era at Different Locations along Alaska's North Slope ............27 


\section{Figures}

1. Map of study area extending from the United States-Canadian border in the east to Cape Beaufort in the west...

2. Example of relict termini on barriers at different locations along the North Alaskan coast from 1980s AHAP aerial imagery.

3. Normalized daily indices of Arctic 0scillation from 1950-2020 and 90-day running average...

4. Map of study area depicting specific eras and barrier chains with no data coverage ...7

5. Aerial images showing example estimates of visually determined tundra vegetation coverage

6. Pie diagrams showing tundra vegetation coverage on barrier islands in North Alaska .....9

7. Plot showing the number of individual barriers per barrier chain for each analysis era from Cape Beaufort to the United States-Canadian border.

8. Plot showing the barrier chain area per length of individual barrier chains for each analysis era from Cape Beaufort to the United States-Canadian border

9. Map showing the mean elevation of barriers and the mean elevation distribution for Chukchi and Beaufort Sea coast barriers based on available light detection and ranging and structure-from-motion from the 2010s-era data

10. Plot of kernel probability density estimates of barrier elevations with and without tundra vegetation present.

11. Map of barrier chains and corresponding boxplots of barrier chain widths for the different time periods for the Beaufort Sea and Chukchi Sea coasts.

12. Plot of kernel probability density estimate of barrier chain width for barriers with and without tundra vegetation present.

13. Map of barrier chains and corresponding boxplots of barrier chain sinuosity over time along the Beaufort Sea and Chukchi Sea coast.

14. Plot of kernel probability density estimate of sinuosity for barriers with and without tundra vegetation present.

15. Maps showing the presence of recurved features on barriers along both the Chukchi and Beaufort Sea coasts for the five analysis eras.

16. Maps showing the presence of relict termini on western and eastern barrier termini along both the Chukchi and Beaufort Sea coasts for the five analysis eras.

17. Maps showing orientation of barrier chains in cardinal degrees along the Beaufort Sea and Chukchi Sea coasts for the five analysis eras and a visual example of changing barrier orientation

18. Maps showing wave conditions at points along the Chukchi and Beaufort Sea coasts as well as mean barrier chain orientation for the 2020s, 2010s, 2000s, and 1980s 


\section{Tables}

1. Study eras, data sources, spatial coverage, and shoreline proxies used .........................6

2. Missing barrier chains in each of the five analysis eras ......................................................6

3. Change in total number of barriers in barrier chains between analysis eras.................10

4. Change in barrier chain area over time ............................................................................11

5. Mean widths of barriers in the study area over time ........................................................14

6. Mean and range of orientation of barriers for the five analysis eras..............................20

\section{Conversion Factors}

International System of Units to U.S. customary units

\begin{tabular}{lll}
\hline \multicolumn{1}{c}{ Multiply } & \multicolumn{1}{c}{ By } & \multicolumn{1}{c}{ To obtain } \\
\hline kilometer $(\mathrm{km})$ & Length & mile (mi) \\
meter $(\mathrm{m})$ & 0.6214 & yard (yd) \\
\hline & 1.094 & \\
\hline square meter $\left(\mathrm{m}^{2}\right)$ & Area & acre \\
hectare (ha) & 0.0002471 & acre \\
square kilometer $\left(\mathrm{km}^{2}\right)$ & 2.471 & square mile $\left(\mathrm{mi}^{2}\right)$ \\
\hline
\end{tabular}

Temperature in degrees Celsius $\left({ }^{\circ} \mathrm{C}\right)$ may be converted to degrees Fahrenheit $\left({ }^{\circ} \mathrm{F}\right)$ as follows: ${ }^{\circ} \mathrm{F}=\left(1.8 \times{ }^{\circ} \mathrm{C}\right)+32$.

Temperature in degrees Fahrenheit $\left({ }^{\circ} \mathrm{F}\right)$ may be converted to degrees Celsius $\left({ }^{\circ} \mathrm{C}\right)$ as follows:

$$
{ }^{\circ} \mathrm{C}=\left({ }^{\circ} \mathrm{F}-32\right) / 1.8 \text {. }
$$

\section{Datum}

Vertical measurements were made in the Universal Transverse Mercator (UTM) coordinate system on the North American Datum of 1983 (NAD 83) using the experimental geoid model xGeoid17b (https://beta.ngs.noaa.gov/GEOID/xGEOID17).

Horizontal position measurements were made in the Alaska Albers Equal Area Conic coordinate system on the North American Datum of 1983 (NAD 83). 


\section{Abbreviations}

$\begin{array}{ll}\text { AO } & \text { Arctic Oscillation } \\ \text { AHAP } & \text { Alaska High-altitude Aerial Photography } \\ \text { aMHW } & \text { approximate mean high water } \\ \text { CUSP } & \text { Continually Updated Shoreline Product } \\ \text { DEM } & \text { digital elevation model } \\ \text { DSAS } & \text { Digital Shoreline Analysis System } \\ \text { ECMWF } & \text { European Centre for Medium-Range Weather Forecasts } \\ \text { ENSO } & \text { El Niño Southern Oscillation } \\ \text { LWI } & \text { land-water interface } \\ \text { MHW } & \text { mean high water } \\ \text { NACCH } & \text { National Assessment of Coastal Change Hazards } \\ \text { NAO } & \text { North Atlantic Oscillation } \\ \text { NOAA } & \text { National Oceanic and Atmospheric Administration } \\ \text { SfM } & \text { structure-from-motion } \\ \text { SST } & \text { sea-surface temperature } \\ \text { T-sheet } & \text { Topographic sheet } \\ \text { USGS } & \text { U.S. Geological Survey }\end{array}$




\title{
Assessment of Barrier Island Morphological Change in Northern Alaska
}

\author{
By Anna I. Hamilton, ${ }^{1}$ Ann E. Gibbs, ${ }^{2}$ Li H. Erikson, ${ }^{2}$ and Anita C. Engelstad ${ }^{2}$
}

\section{Abstract}

Arctic barriers islands are highly dynamic features influenced by a variety of oceanographic, geologic, and environmental factors. Many Alaskan barrier islands and spits serve as habitat and protection for native species, as well as shelter the coast from waves and storms that cause flooding and degradation of coastal villages. This study summarizes changes to barrier morphology in time and space along the North Slope coast of Alaska between the United States-Canadian border and Cape Beaufort from 1947 to 2020. Changes considered in this study include number of barriers, area and perimeter, shoreline length, barrier sinuosity and width, presence and number of relict terminus features, presence and coverage of tundra vegetation, barrier orientation, and elevation metrics. Wave conditions are also summarized and related to changes in barrier morphology. The results in this report help to better predict future barrier evolution and prevalence along Alaska's coast by increasing our understanding of Arctic barrier development, migration and degradation.

\section{Introduction}

Arctic barrier islands make up 23 percent of global barriers and are geomorphologically distinct from their temperate and tropical counterparts owing to complex cryosphere processes and formations (Stutz and Pilkey, 2011). Many Alaskan barrier islands and spits serve as habitat and provide protection to birds, polar bears, walruses, and fish. Furthermore, barriers shelter the coast from waves and storms that cause flooding and degradation, protect coastal villages from the direct onslaught of waves, and protect existing and planned oil and gas infrastructure situated on the mainland or in lagoons between the barriers and mainland coast.

The U.S. Geological Survey (USGS) is assessing Alaskan barrier islands and spits, collectively referred to as barriers throughout this report, in order to improve upon the fundamental understanding of barrier formation, evolution, and stability in a permafrost setting. The greater purpose of the project is to improve upon the understanding of Arctic barrier development, migration

${ }^{1}$ University of Copenhagen.

${ }^{2}$ U.S. Geological Survey. and degradation, and apply this knowledge to predict future barrier evolution and prevalence along Alaska's coast. This report is the first in a series to summarize historical morphological changes to barriers along the north coast of Alaska between the United States-Canadian border and Cape Beaufort (fig. 1). These results may then be used to advance our understanding of barrier island dynamics in Arctic environments and modelling decadal- to multidecadal-scale barrier evolution.

Previous reports have quantified Arctic Alaska barrier island change rates, bluff erosion, and ice extent, and described the region's coastal morphology (Hopkins and Hartz, 1978; Gibbs and Richmond, 2015, 2017; Gibbs and others, 2019). Alaska barrier coasts have been shown to be predominantly erosional, and erosion rates are approximately five times higher along the Beaufort Sea coast than along the Chukchi Sea coast. Accretion rates are, however, similar along these coastlines (Gibbs and Richmond, 2015). Arctic barriers have eroded as much as 25 meters per year ( $\mathrm{m} / \mathrm{yr})$, decreased in net area, and shown a tendency to rotate and migrate to the southwest along with prevailing winds and nearshore currents (Ravens and Lee, 2007; Gibbs and Richmond, 2015, 2017).

\section{Arctic Barriers and Sea-Ice Processes}

Arctic barriers are highly dynamic and influenced by the extent and duration of seasonal sea ice, wave heights and water levels, the presence of permafrost and vegetation, temporal variations in available sediment, thermomechanical erosion, and other oceanographic, geologic, and environmental factors (Hopkins and Hartz, 1978; Stutz and Pilkey, 2011). Land-based sediment supply along Arctic tundra coasts is often limited by the presence of permafrost that consists of bounded fine sediment and massive ice segments with low clastic sediments. Eroded material is therefore composed largely of ice and organic material, and little clastic sediment (Jorgenson and Brown, 2005).

Two common Arctic barrier formation processes result in either remnant islands or constructed islands and are described below. On a geologic timescale, thermokarst processes produce remnant islands as inundation and breaching of thermokarst lakes leads to separation from the mainland (Hopkins and Hartz, 1978; Ruz and others, 1992; Stutz and Pilkey, 2011). Such barriers can be later modified by spits 


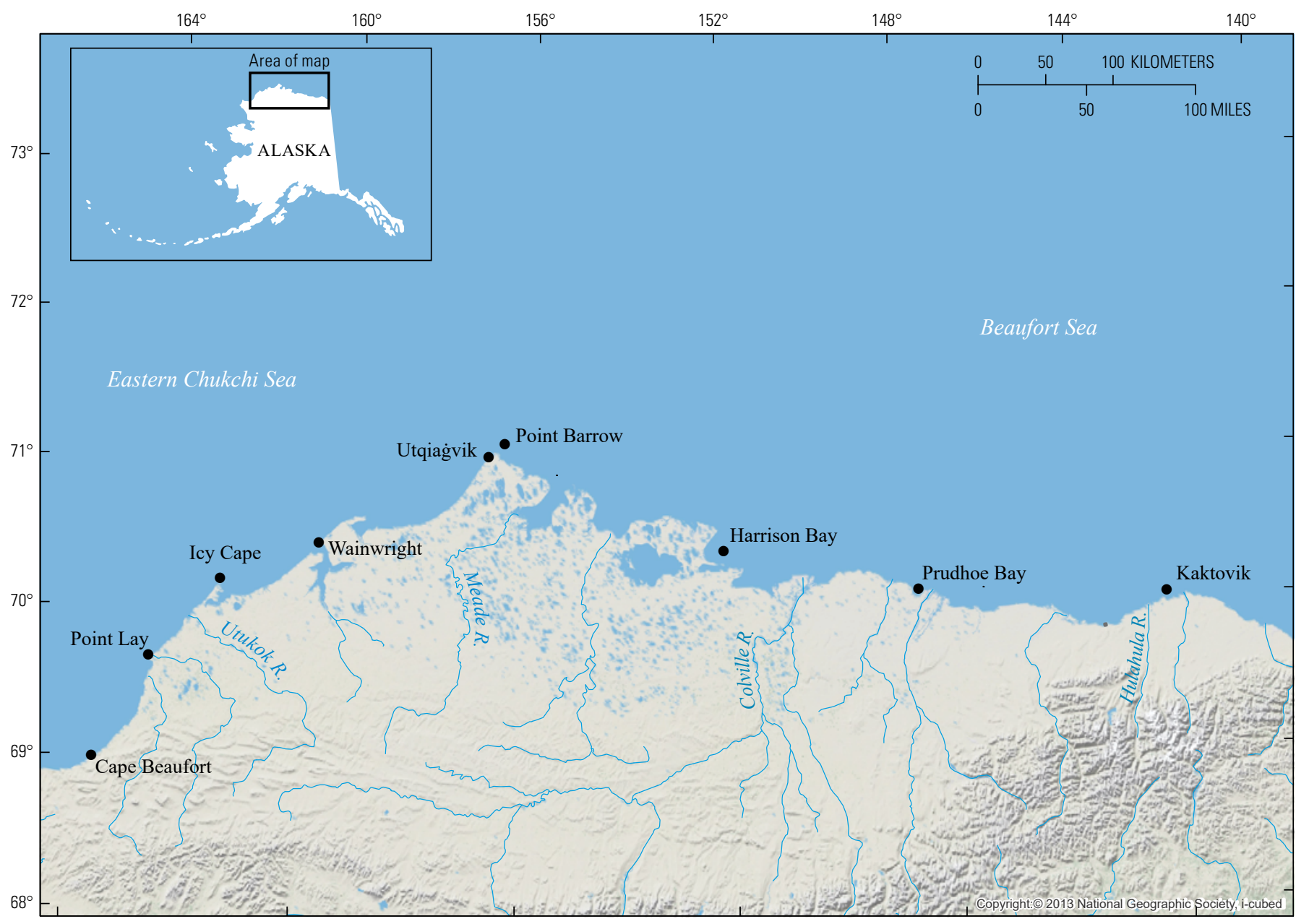

Figure 1. Map of study area extending from the United States-Canadian border in the east to Cape Beaufort in the west.

that form on remnant barrier terminal ends through longshore transport of sediment eroded by storms and waves (Ruz and others, 1992). Similar to spit formation along remnant barriers, constructed barriers are produced through littoral drift, longshore transport, and waves driven by the prevailing wind that deposit sediment parallel to the coast when sediment supply is sufficient (Hopkins and Hartz, 1978; Short, 1979; Morack and Rogers, 1982). Although sea-ice cover inhibits wave energy and fetch for all but about three months of the year (Barnhart and others, 2014), the open water season may be extended as the climate changes (Thomson and Rogers, 2014). As a result, traditional barrier formation mechanisms may become more important with time.

For both remnant and constructed barriers, the short ice-free season is already long enough to develop and rework complex spit features at the ends of islands. For example, overwash or changing wave directions combined with continued longshore transport and discontinuous sediment supply can produce new spit features that continue to grow past the previously formed terminus of barriers (Hopkins and Hartz, 1978; Short, 1979; Petersen and others,
2008). Over time, multiple finger-like, relict termini may exist along the lagoon shore of the barrier (fig. 2).

Other sea-ice processes can also influence barrier morphology. For example, freely drifting ice or pack iceexpanses of large pieces of floating ice coalescing into a nearly continuous mass - that are rafted (pushed) by ocean currents, surging water levels, and (or) winds are known to cause ridges of sediment on the beach face and steep berms (Barnes and Reimnitz, 1987). Rafting of sediment also occurs by ice-gouging and entrainment of sand-sized particles into anchored (bottom-fast) ice that forms during fall storms and is transported the following year during spring/summer break up (Kempema and others, 1989; Eicken and others, 2005). Anchor ice and sediment entrainment occur when turbulent waters are exposed to below freezing temperatures (supercooled) forming "sticky" frazil ice crystals that freeze in place and adhere to the seabed. The amount of sediment entrained in ice varies yearly and depends both on location and storm severity post-freeze. Storms can cause additional entrainment when frazil ice is formed as turbulent seas are cooled (Kempema and others, 1989). 


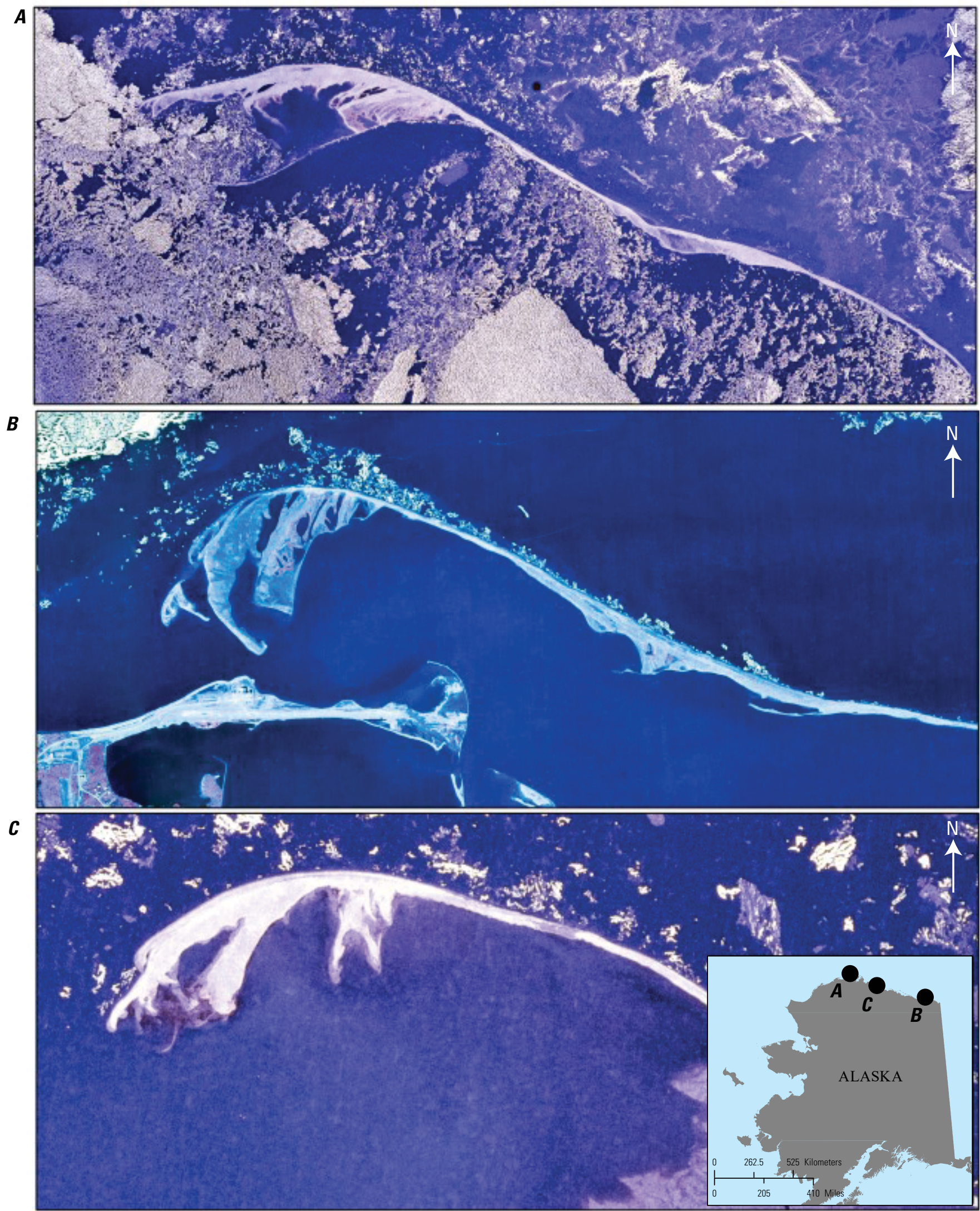

Figure 2. Aerial image examples of relict termini on barriers at different locations along the North Alaskan coast from 1980s-era Alaska High-altitude Aerial Photography. A, Plover Islands. B, Bernard Spit. C, Pogik Point. 
Further exploration of Arctic barrier formation and their development in relation to changing wind and wave conditions and other climatic factors, such as cryospheric processes, can help models predict the evolution of Arctic barriers and their distinct features.

\section{Impact of Temperature Changes in the Arctic}

Local and global oceanographic properties are changing owing to warming temperatures, and the Arctic is especially vulnerable because of positive feedbacks between snow loss and ice cover (Douglas, 2010). Intensified solar heating, thinning of sea ice, and sediment entrainment all contribute to the decline of snow and ice cover, which decreases the surface albedo (proportion of reflected heat). A lower surface albedo further increases heating and ice thinning, reducing sea ice extents and durations (Shapiro Ledley and Pfirman, 1997; Pithan and Mauritsen, 2014; Kashiwase and others, 2017; Stuecker and others, 2018). Understanding these changes is necessary for ensuring the viability of existing and future infrastructure by reducing the risk potential for erosion and flooding and improving the general safety of communities and habitats.

In both the Beaufort and Chukchi Seas, sea ice extent and duration have been decreasing since the 1950s (Onarheim and others, 2018). A decrease in sea ice extent coupled with warming temperatures has caused a delay in the freezing of Arctic seas leading to an approximately 3 week longer ice-free period in the autumn since the 1980s (Johnson and Eicken, 2016). This delay in freezing prevents nearshore pack ice from forming, which otherwise protects the coast from flooding and erosion by acting as a barrier to storm surge and high waves. The tundra landscape is also affected by temperature increases that thaw the underlying permafrost, which plays a key role in preventing erosion of the landscape and keeping the land habitable along the northwestern Alaskan coast. Upper layers of permafrost have increased in temperature by as much as 3 degrees Celsius since the 1980s. Depending on the distribution of thawing, this can cause substantial change to the landscape by decreasing soil strength and increasing permeability (Lachenbruch, 1994). Such changes encourage increased water flow, which allows for increased advective heat transfer and accelerated melting that can progress to ice collapse and other disruptions in the landscape (Lachenbruch and Marshall, 1986; Osterkamp and Romanovsky, 1999).

\section{Atmospheric Oscillations and their Influence in the Arctic}

Large-scale, atmospheric oscillations including the El Niño Southern Oscillation (ENSO), North Atlantic Oscillation (NAO), and the Arctic Oscillation (AO) have a considerable influence on global climatic patterns and are a good indication of natural climate variability. Shifts in these indices influence Arctic atmospheric and oceanographic patterns (Rigor and others, 2002; Liu and others, 2004; Delworth and others, 2016) and may invoke corresponding changes in barrier morphology.
On a decadal scale, ENSO and NAO influence sea ice thickness. Spring Arctic sea ice thins faster after a winter El Niño event. As this ice thins, the more resilient multiyear sea ice becomes less prominent (Maslanik and others, 2007). In the Beaufort Sea, this phenomenon has been observed to affect the sea ice thickness by as much as 50 percent (Liu and others, 2004). The NAO has a strong influence on North America, Greenland, and Europe, and positive NAO leads to a stronger than normal subpolar low- and subtropical high-pressure belts. This increased pressure difference leads to a northward shift in storm tracks. Positive NAO can also decrease Arctic sea ice cover, especially in winter, because of the poleward transport of warmer air temperatures. Variations in the NAO can induce multidecadal climate variability in the Northern Hemisphere that leads to sea ice loss in the Arctic (Delworth and others, 2016).

Arctic atmospheric circulation patterns are directly affected by the $\mathrm{AO}$, and a positive phase causes the jet stream to be farther north than average, shifting storms toward the Arctic (fig. 3). Changes to Arctic winds can also cause changes to drifting sea ice as seen during a positive $\mathrm{AO}$ phase, where old sea ice is pushed out of the Arctic Ocean. A negative phase causes a southward shift of the jet stream and fewer Arctic storms in addition to encouraging more of the older, thicker ice to stay in the middle of the Arctic Ocean (Liu and others, 2004).

The relations between the climate indices described above and barrier morphology in the Arctic has not been investigated. However, it is worth considering these indices in relation to barrier change as there are possible connections between the Arctic climate and these indices.

\section{Changing Wave Conditions}

The Arctic Ocean can be described by its low tide range, seasonally changing ice cover, and, relative to some lower latitude oceans, slow-moving currents, and low-energy waves (Walker, 1984). Despite being influenced by ice most of the year, waves are a dominant physical process driving the morphodynamics of barriers in the Arctic Ocean. Waves in the Beaufort and Chukchi Seas are controlled by wind and the duration and amount of ice-free water available to generate surface waves (Thomson and others 2016). Coincident with the delay in the timing of the autumn ice advance, there is a trend toward stronger autumn storms (Serreze and others, 1993, 2001; Zhang and others, 2004). Clear trends in the annual duration of the open water season and in the extent of the seasonal sea ice minimum suggest that the sea state - the general condition of the free surface of a large body of water with respect to wind waves and swell at a certain location and moment - should be increasing, independent of changes in the wind forcing. This is supported by evidence of increasing wave energy along the coast of northern Alaska, which is corroborated by satellite altimeter estimates of wave energy (Thomson and others, 2016).

Changes to Arctic barriers are mostly attributed to these changing wave climates, similar to many lower latitude barriers, as well as ice processes unique to the Arctic. However, the exact causes for the overall degradation of barriers are 


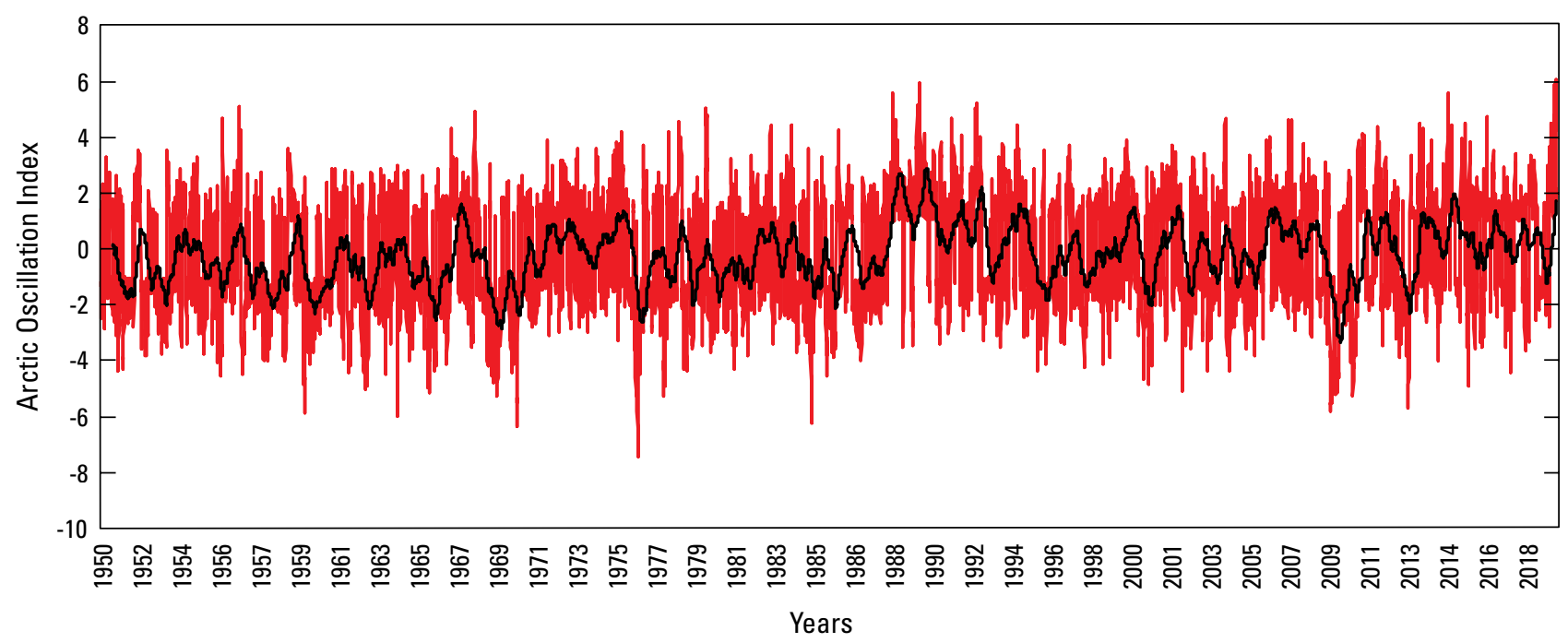

\section{EXPLANATION}

\section{— Normalized daily indices of Arctic Oscillation 1950-2020 \\ — 90 percent moving average (normalized daily indices of Arctic Oscillation 1950-2020)}

Figure 3. Plot of normalized daily indices of Arctic 0 scillation (AO) from 1950 to 2020 and 90-day running average (data from National Oceanic and Atmospheric Administration, 2020).

not fully understood (Stutz and Pilkey, 2011). Factors such as sediment supply, sea-level rise, wave energy, changes to storm strength or frequency, and sediment entrainment in sea ice are all relevant factors that may contribute to the observed morphological variations. Understanding how these parameters shape Arctic barriers is crucial to projections of future stability and patterns of migration. This report will explore morphologic change in the context of the aforementioned environmental and climatic factors.

\section{Methods}

\section{Shoreline Datasets}

Barrier shoreline data were compiled from multiple sources including Gibbs and others (2017), Snyder and Gibbs (2019), and the National Oceanic and Atmospheric Administration (NOAA) Continually Updated Shoreline Product (CUSP; NOAA, 2019). This combined dataset is intended to be expanded upon and updated as more data become available in the coming years. The datasets map different shoreline proxies, including approximate mean high water (aMHW), instantaneous land-water interface (LWI), and mean high water (MHW) (Gibbs and Richmond 2015; Gibbs and others, 2019; NOAA, 2019). The source, time period, spatial coverage, and shoreline proxy used for each dataset are listed in table 1 . The vertical datum for the light detection and ranging (lidar) and structure-from-motion (SfM) elevation data is the experimental GEOID model xGEOID17b, which approximates the mean sea level in the region. The barriers in the study area were subdivided into 42 barrier chains based on location and continuity (appendix 1). Shoreline data were used to create the polygons that the morphometric changes are based upon. The locations of major island chains and gaps in data coverage are shown in figure 4.

To assess change to barrier morphology over time, the shoreline data were divided into five analysis time periods, or eras: circa-1950s, 1980s, 2000s, 2010s, and 2020s These divisions are based on regional-scale mapping and image acquisition campaigns and thus, individual years may cross decadal boundaries (table 1). The 2020s-era data include only the most recent shorelines, since 2016, and are therefore not as spatially comprehensive as data from the other eras (fig. 4). The 2010s-era data are more spatially accurate and complete, compared to the 2020s data, but are not necessarily the most recent data available. Shorelines in the 2010 s era were derived from high-resolution ( $<1$ meter) lidar and SfM data and are more accurate ( 2 to 15 meter [m] positional uncertainty) compared to the most recent 2020s-era shorelines derived from satellite imagery (4 to $23 \mathrm{~m}$ positional uncertainty). In addition, the NOAA CUSP dataset uses a MHW shoreline proxy, whereas the 1980s, 2000s, and 2010s data use a LWI shoreline proxy.

Among the morphometric parameters calculated was barrier sinuosity, which was measured by dividing the open-coast shoreline length by the along-coast straight line distance between barrier end points. By this calculation, a larger value indicates greater sinuosity. Note that in regions where shoreline data are 
Table 1. Data sources, spatial coverage, and shoreline proxies for each of the five analysis eras used in this study.

[T-sheet, topographic sheet; lidar, light detection and ranging; DEM, digital elevation model; SfM, structure from motion; aMHW, approximate mean high water; LWI, instantaneous land-water interface; MHW, mean high water]

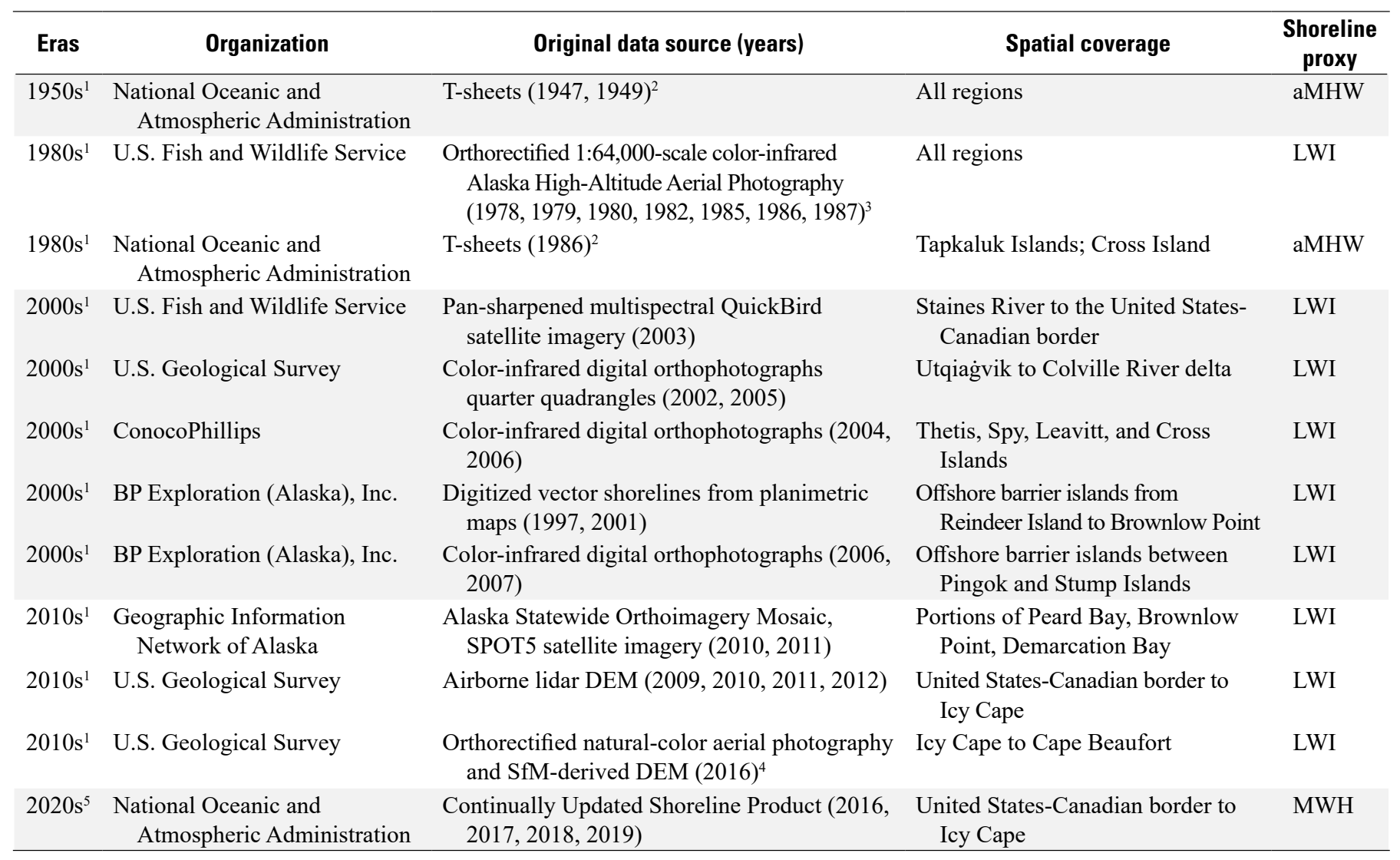

${ }^{1}$ Gibbs and others, 2017; Snyder and Gibbs, 2019.

${ }^{2}$ NOAA shoreline survey scans (T-sheets and TP-sheets); available at https://nosimagery.noaa.gov/images/shoreline_surveys/survey_scans/NOAA_Shoreline_Survey_ Scans.html, accessed April 20, 2019.

${ }^{3}$ Orthorectified by S. Arko, University of Alaska Fairbanks, in 2014 under contract with the U.S. Fish and Wildlife Service.

${ }^{4}$ Fairbanks Fodar, dba for Jago River Air, LLC.

${ }^{5}$ NOAA, 2019.

Table 2. Missing barrier chains in each of the five analysis eras.

\begin{tabular}{cl}
\hline Era & \multicolumn{1}{c}{ Missing barrier chains } \\
\hline $1950 \mathrm{~s}$ & None \\
\hline $1980 \mathrm{~s}$ & $16-18,20,25$ \\
\hline $2000 \mathrm{~s}$ & $32-42$ \\
\hline $2010 \mathrm{~s}$ & None \\
\hline $2020 \mathrm{~s}$ & $5,11,25-27,29-31,35,39-42$ \\
\hline
\end{tabular}

missing (fig. 4), for example along the eastern Chukchi Sea coast for the 2000s-era, changes to morphology are considered to have no data. Eras for which specific barrier chains have no data are removed from comparative analyses.

\section{Barrier Morphometrics and Change}

Vector shapefiles of barrier shorelines were converted to polygons, and previously unmapped barriers and missing segments were digitized. Polygons for spits and barrier beaches were closed at the transition point to the mainland. Barrier polygons and polyline shorelines were used to calculate the following morphometrics of each barrier in each study era: number of islands (in each barrier chain), type (constructed or remnant), area (in square meters $\left[\mathrm{m}^{2}\right]$ ), perimeter length (in meters), exposed-shoreline length (length in meters of the shoreline on the exposed coast), straight-line length (length in meters between the western- and eastern-most points of the exposed shoreline), sinuosity (the ratio between exposedshoreline length and straight-line length), width (mean, maximum, minimum, and 25th and 75th percentiles), presence or absence of recurved features on either end of the island, presence and number of relict terminus features on either end of the island, presence of 


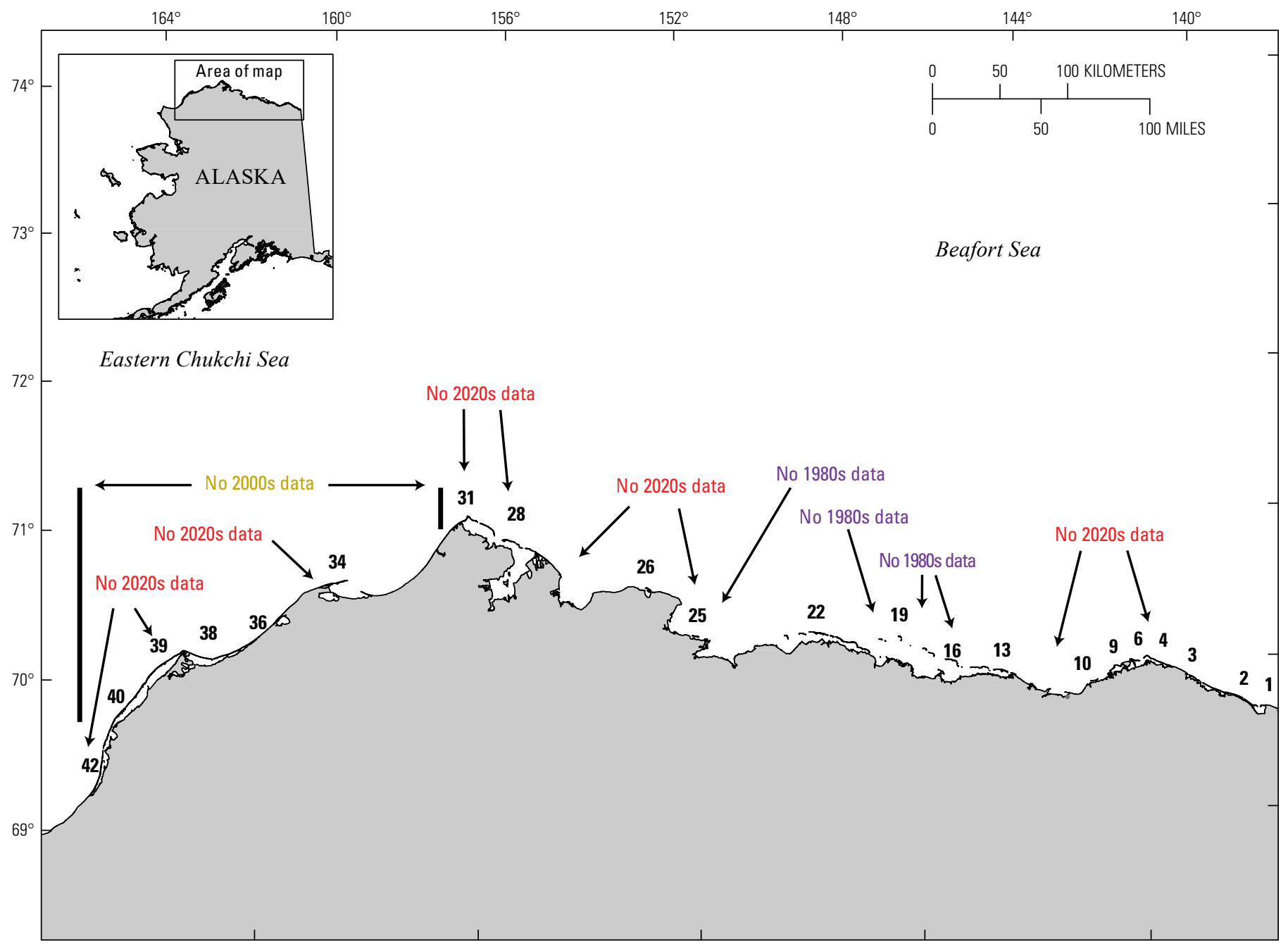

Figure 4. Map of study area on the North Slope of Alaska depicting specific eras and barrier chains with no data coverage. Barrier chains numbered east to west, from the United States-Canadian border to Cape Beaufort. Map base from Alaska Department of Natural Resources, 1:63,360-scale digital coastline data, 1998.

tundra vegetation and approximate vegetation cover (for 1980s-era only), as well as barrier chain orientation (maximum, minimum, mean, median, and 25th and 75th percentiles). Elevation metrics, including mean, maximum, minimum, and median elevation, were extracted for all 2010s-era barrier polygons based on the 1-meter resolution digital surface models derived from 2010s-era lidar and SfM elevation datasets using the "Zonal Statistics as Table" tool in ArcMap, which summarizes statistics for a zone defined by the polygon(s) provided.

The number of barriers in each island chain, barrier area, and perimeter length were similarly calculated from the polygon shapefiles in ArcMap. Exposed-shoreline and straight-line lengths were then calculated from vector shapefiles. Widths were calculated using transects created with the Digital Shoreline Analysis System (DSAS) v. 5 tool (Himmelstoss and others, 2018). Transects were cast with 50-m spacing using existing offshore baselines from Gibbs and others (2017) and Snyder and Gibbs (2019) and then clipped to the barrier perimeter boundary.
Width statistics were calculated for each barrier chain and each individual barrier using MATLAB. Barrier chain orientation statistics were also calculated in MATLAB using the $\mathrm{X}$ and $Y$ points of transect intersections along the exposed shoreline. Presence of recurved features at the barrier terminus, as well as the number of relict termini, was visually identified.

The presence or absence of tundra vegetation and the approximate percentage covered on individual barriers was determined visually from the 1980s-era, color-infrared Alaska High-Altitude Aerial Photography (AHAP) photomosaics, because it was the only dataset with nearly complete and temporally consistent image coverage for the study area. Tundra vegetation coverage was interpreted as quartile percentages ( 0 percent, less than 25 percent, 25 to 50 percent, 50 to 75 percent, and greater than 75 percent; fig. 5). Barriers with tundra presence are classified as remnant barriers, which have been isolated from the tundra mainland through thermal erosional and thermokarst processes 
whereas barriers without tundra vegetation are classified as constructed barriers, which are accumulations of sand and gravel (Hopkins and Hartz, 1978). Barriers may exhibit signs of both remnant and constructed formation processes, and additional field data, such as core sampling, are needed to affirm barrier construction mechanisms. Still, the presence or absence of tundra vegetation is an important piece of data for understanding and distinguishing between these two types of formation processes. Owing to gaps in the image data, and the presence of cloud and ice cover, there is likely an underestimation of the tundra presence and coverage estimates. Additionally, because of seasonal fluctuations and long-term changes, the data likely do not reflect current ground conditions.

A distinction has been made between the active terminus, which refers to the current terminus of the barrier, and relict terminus, which is a previously formed terminus that has since been overtaken by a new, active terminus. At some locations, there can be multiple active and relict termini where bifurcations develop in association with the start of recurvature in the terminal shoreline (fig. $5 C$ ). When identifying relict termini, this study considers whether
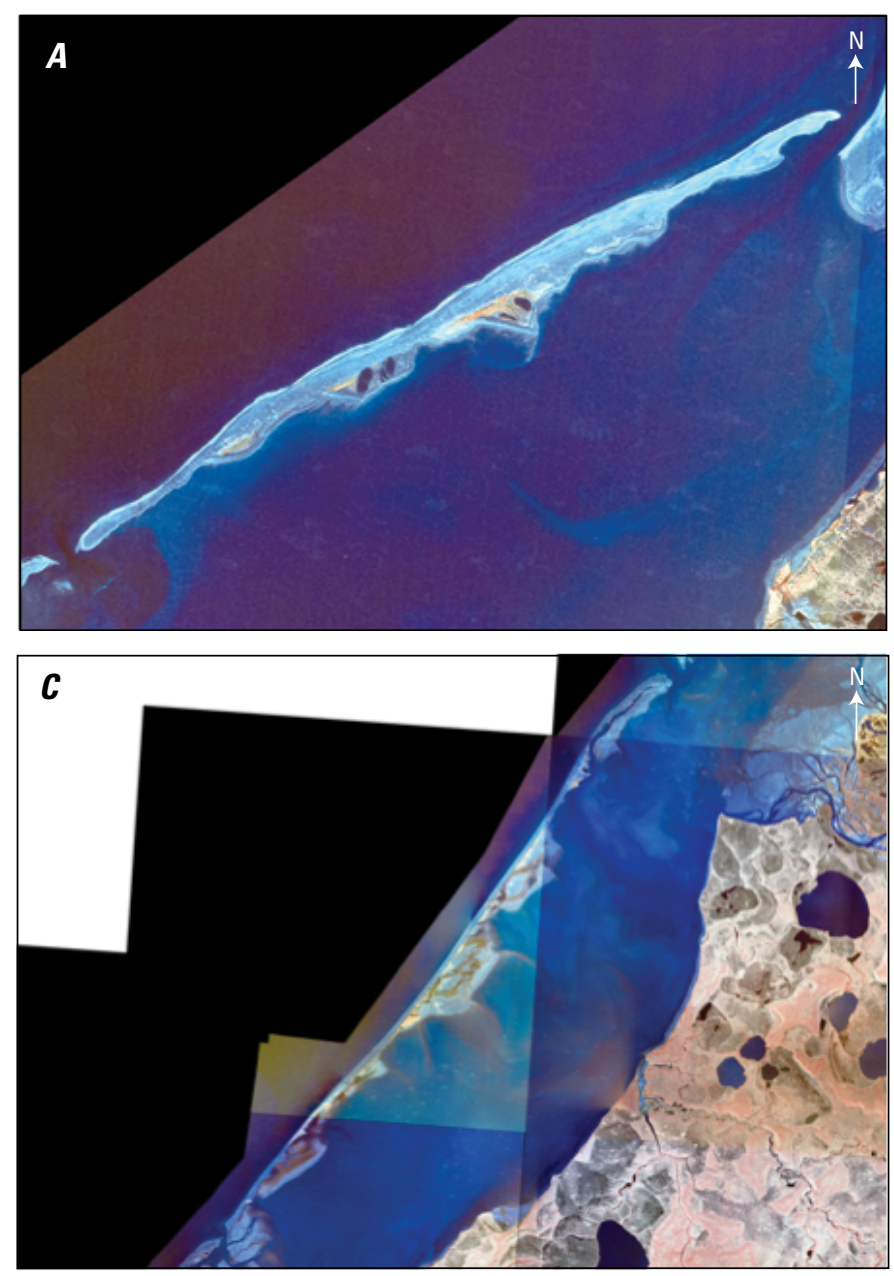

individual termini remain exposed to the coast and considers termini as relict only when direct exposure to ocean waves is fully lost. Recurvature refers to the active terminus at either end of a barrier and is considered present when the barrier makes a distinct curve, often forming arcuate or crescentic islands (as seen in fig. $5 B$ and 5D).

To facilitate the identification of differences in oceanographic influences, as well as compare regional trends in morphometric data, the results from this study are presented in the context of their respective coastal regions along the Beaufort and Chukchi Seas. Additionally, short-term temporal comparisons are made from era to era and long-term comparisons are made between both the 1950s and 2010s as well as between the 1950s and 2020s eras.

\section{Wave Climate}

Change in the wave climate over time was evaluated with the fifth generation European Centre for Medium-range Weather Forecasts (ECMWF ERA5; Hersbach and others, 2019) atmospheric and ocean reanalysis of the global climate.
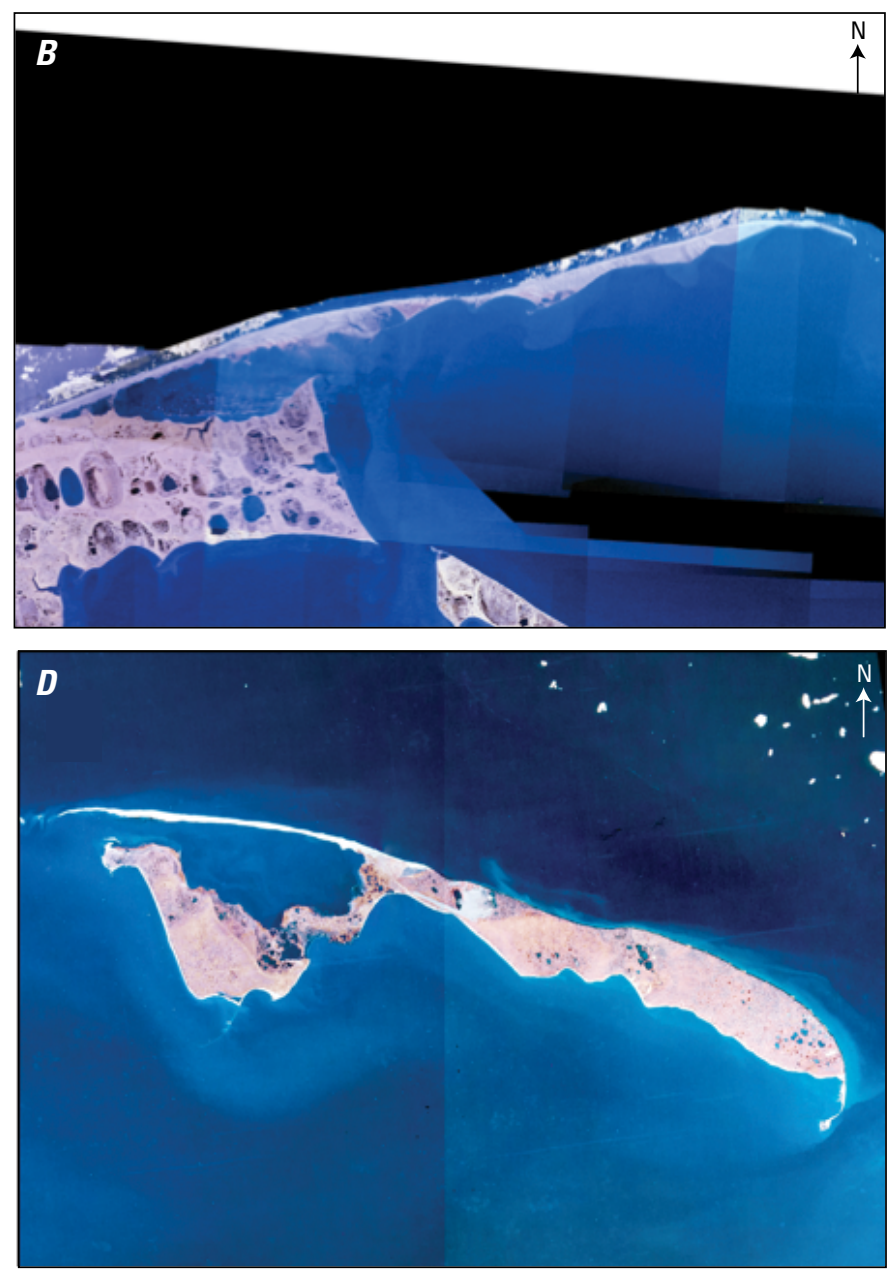

Figure 5. Aerial images showing example estimates of visually determined tundra vegetation coverage. $A$, Less than 25 percent at barrier chain 39; $B, 25$ to 50 percent at barrier chain 34; $C, 50$ to 75 percent at barrier chain 40; $D$, Greater than 75 percent at barrier chain 13 . 
Reanalysis combines model data with observations from across the world into a globally complete and consistent dataset. Hourly wave data (significant wave height [the mean of the highest $1 / 3$ of waves], mean direction, and mean wave period) for the ice-free season between June to November were extracted for the years between 1979 to 2019. Nearshore grid points were downloaded from the ECMWF website ${ }^{1}$ and used to compute changes in the wave climate. The effect of changing wave direction over time is also considered in relation to barrier orientation.

\section{Results}

Results from this study, including vector shorelines with data sources and polygons with morphometric data, are available in the associated data release (Hamilton and others, 2021).

\section{Tundra Presence and Percentage Covered}

Tundra vegetation was identified on 21 (approximately 17 percent) of the 1980s barriers in the study area, most of which (16, or 13 percent) were along the Chukchi Sea coast, with far fewer (5, or 4 percent) along the Beaufort Sea coast (fig. 6). On barriers where tundra vegetation was present, the percentage covered was relatively low on Chukchi Sea coast barriers ( 7 of 16 barriers, or 44 percent, had less than 25 percent coverage) compared to Beaufort Sea coast barriers ( 4 of 5 , or 80 percent, had greater than 25 percent vegetation coverage).

\section{Number of Barriers}

The change in the number of barriers, and whether that change is caused by barrier formation or degradation, is an important indication of the stability of the barrier system. Factors that can contribute to uncertainties in the number of barriers mapped, and therefore counted in each island chain, include the shoreline datum or proxy being mapped, the water level at the time the image was taken, and (or) the ability to distinguish exposed, low-lying land from the water surface in the lidar digital elevation model (DEM) dataset.

Overall, the number of barriers along the entire study area decreased over time, with 173 barriers accounted for in the 1950s, 123 in the 1980s, and 120 in the 2010s (these are the most complete datasets). Table 3 presents the change in number of barriers between each study era and highlights where chains are primarily gaining, losing, or unchanging. Despite the general decrease in number of barriers, barrier chains are relatively stable in the Chukchi Sea (table 3 and fig. 7). However, lack of imagery of the Chukchi Sea coast in the 2000s requires caution in interpreting this result.

${ }^{1}$ Available at https://cds.climate.copernicus.eu/cdsapp\#!/dataset/reanalysisera5-single-levels?tab=form.

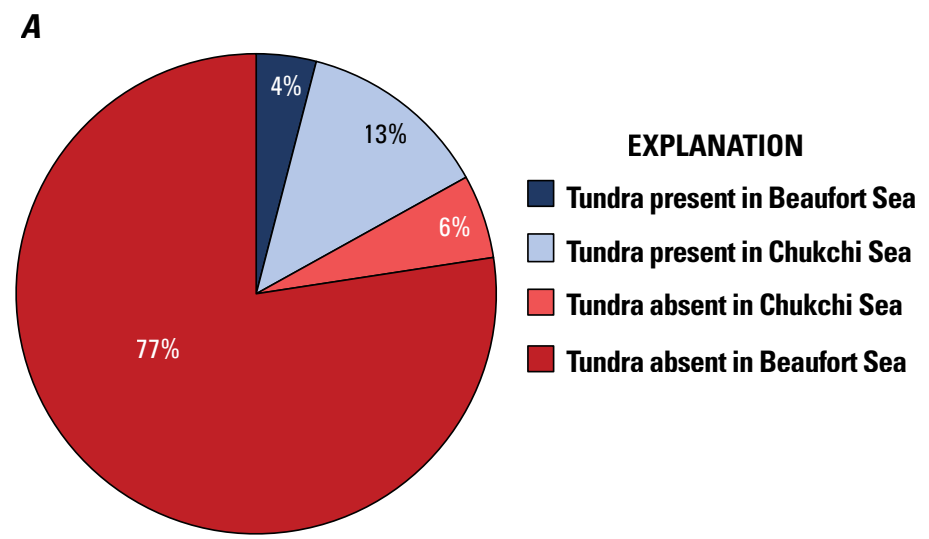

B. Beaufort Sea coast

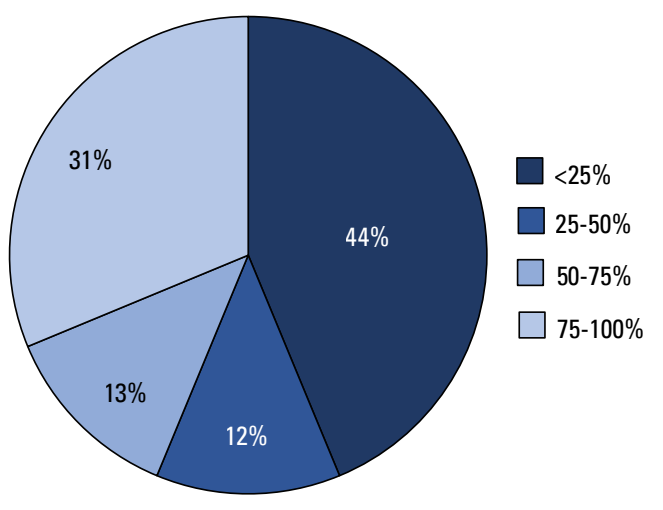

C. Chukchi Sea coast

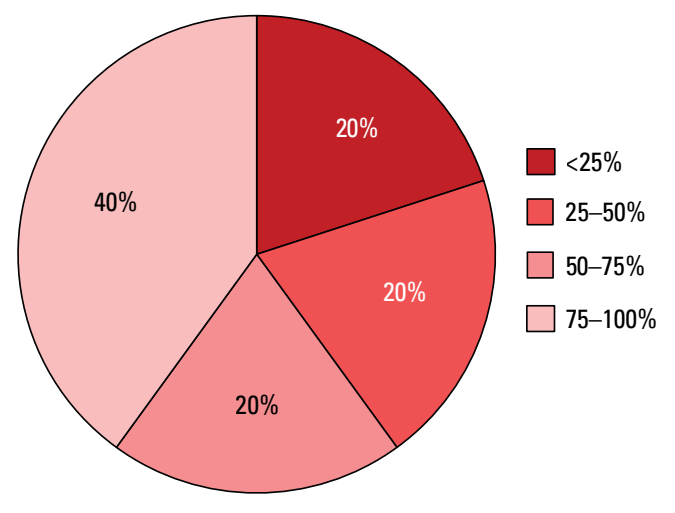

Figure 6. Pie diagrams showing tundra vegetation coverage (in percent [\%]) on barrier islands in North Alaska. $A$, Presence and absence of tundra vegetation on all barriers within the study area, as interpreted from 1980s-era Alaska High-Altitude Aerial Photography imagery. $B$, Approximate percentage covered by tundra vegetation on islands where tundra vegetation was identified on the Chukchi Sea coast. $C$, Approximate percentage covered by tundra vegetation on islands where tundra vegetation was identified on the Beaufort Sea coast. 
Table 3. Change in total number of barriers in barrier chains between analysis eras for the study area in North Alaska.

[Values are percentages]

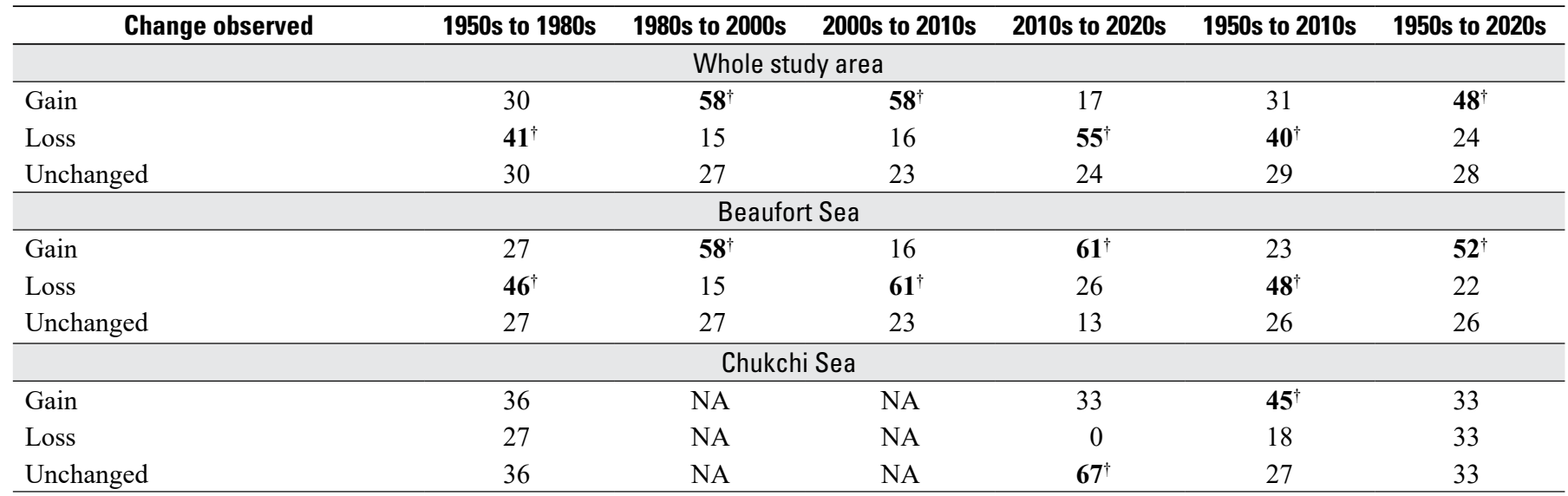

${ }^{\dagger}$ and bold numbers indicates the highest percentage.

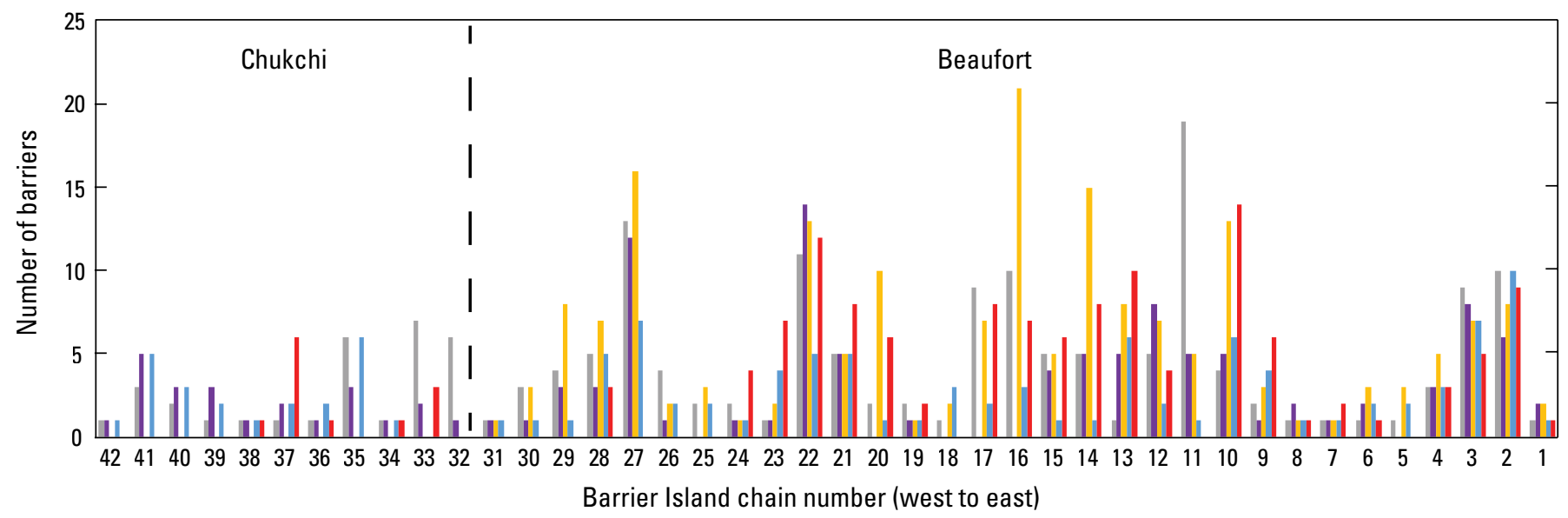

EXPLANATION

$\square$ 1950s $\square$ 1980s $\square 2000 s \quad \square 2010 s \quad \square 2020 s$

Figure 7. Plot showing the number of individual barriers per barrier chain for each analysis era from Cape Beaufort (west) to the United States-Canadian border (east). Barrier chain number reflects the number assigned based on location from the east to west edges of the study area.

Conversely, barrier chains in the Beaufort Sea fluctuate between increasing and decreasing numbers of barriers in barrier chains over time. The greatest short-term changes in the Beaufort Sea occur where the majority of barrier chains (61 percent) experienced both a loss (2000s to 2010s, 116 chains) and a gain (2010s to 2020s, 73 chains) in number of barriers. Despite an overall loss of individual barriers between the 1950s and 2010s, barrier chains in the Chukchi Sea have still gained chains, indicating that the losses in the Beaufort Sea outweigh the gain in barriers along the Chukchi Sea. Notably, the relatively high image resolution of the 2010 s data may allow for more detailed identification of individual barriers, partly accounting for the large difference in number of barriers identified using the 2010 s data versus the lower resolution 2020s data.

\section{Barrier Area}

Barrier area fluctuated between eras, generally increasing between the 1950s and 1980s, decreasing into the 2000s, increasing into the 2010s, and finally decreasing into the 2020 s (table 4). Individual chains were found to be relatively stable over time; however, some notable changes can be seen in, for example, chains 1, 5, 13, and 22 (fig. 8). Again, it should be noted that changes involving the 2020s data are largely affected by differences in data coverage and quality. Specifically, the 
Table 4. Change in barrier chain area per length of barrier, over time, for the study area in North Alaska.

$\left[\mathrm{m}^{2} / \mathrm{m}\right.$, square meter per meter; $\mathrm{m}^{2} / \mathrm{m} / \mathrm{yr}$, square meter per meter per year]

\begin{tabular}{|c|c|c|c|c|c|c|}
\hline Observation & 1950 s to $1980 \mathrm{~s}$ & 1980 s to 2000 s & 2000 s to 2010s & 2010 s to 2020 s & 1950s to 2010s & 1950s to 2020s \\
\hline \multicolumn{7}{|c|}{ Entire study area } \\
\hline Rate of change $\left(\mathrm{m}^{2} / \mathrm{m} / \mathrm{yr}\right)^{1}$ & 9 & -2 & 12 & -19 & 8 & 3 \\
\hline Area $\left(\mathrm{m}^{2} / \mathrm{m}\right)$ & 189 & -52 & 220 & -190 & 428 & 155 \\
\hline Rate of change $\left(\mathrm{m}^{2} / \mathrm{m} / \mathrm{yr}\right)^{1}$ & 5 & -2 & 12 & -19 & 6 & 2 \\
\hline Rate of change $\left(\mathrm{m}^{2} / \mathrm{m} / \mathrm{yr}\right)^{1}$ & 4 & $\mathrm{NA}^{2}$ & $\mathrm{NA}^{2}$ & 0 & 2 & 1 \\
\hline
\end{tabular}

${ }^{1}$ Data are based on maximum number of years between eras. For $1950 \mathrm{~s}$ to $1980 \mathrm{~s}=40$ years, $1980 \mathrm{~s}$ to $2000 \mathrm{~s}=29$ years.

${ }^{2}$ Only island chains with data in both eras being compared are used to avoid over or underestimations of area change.

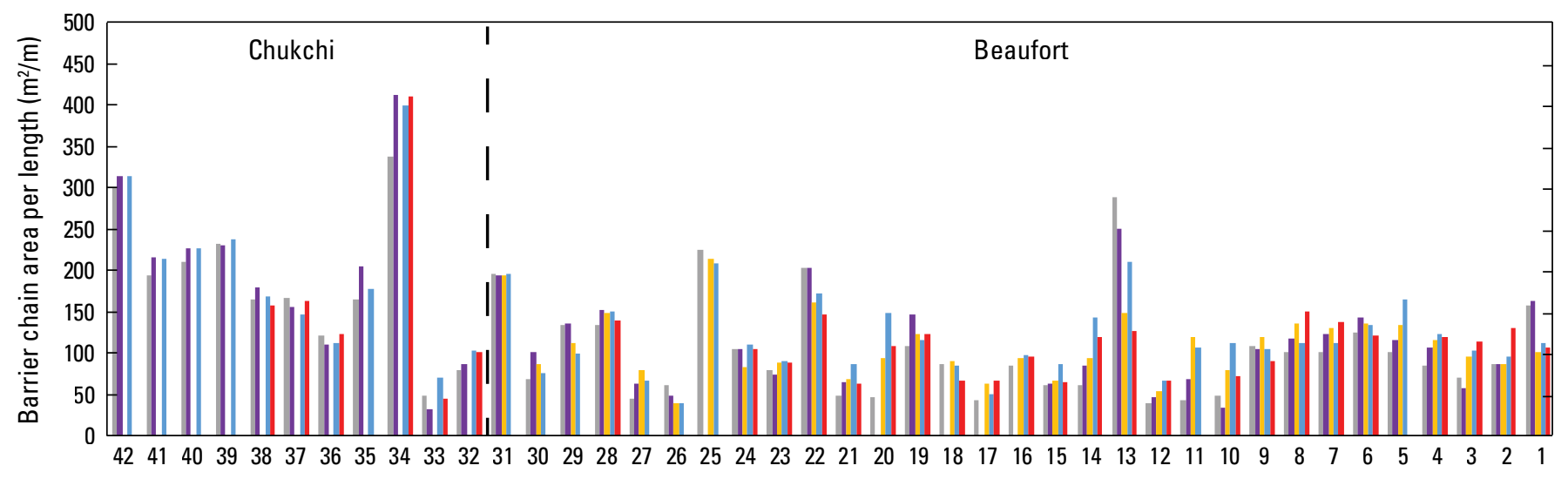

Barrier Island chain number (west to east)

\section{EXPLANATION}

$\square$ 1950s $\square 1980 \mathrm{~s} \square 2000 \mathrm{~s} \square 2010 \mathrm{~s} \square 2020 \mathrm{~s}$

Figure 8. Plot showing the barrier chain area per length (in square meters per meter $\left[\mathrm{m}^{2} / \mathrm{m}\right]$ ) of individual barrier chains for each analysis era from Cape Beaufort (west) to the United States-Canadian border (east). Barrier chain number reflects the number assigned based on location from the east to west edges of the study area. Barriers are separated by location in the Chukchi and Beaufort Seas.

use of CUSP shorelines in the 2020s (table 1) may lead to a relative underestimation of total barrier area reported for that era. Over the long term (1950s to 2010s), total barrier area increased by nearly 20 million $\mathrm{m}^{2}$ ( 9 square meters (area) per length of the barriers (meter) per year $\left[\mathrm{m}^{2} / \mathrm{m} / \mathrm{yr}\right]$ ) across the entire North Slope (appendix 2). Most of this increase in area occurred in the larger region of the Beaufort Sea. Short-term losses were also found to be prevalent in the Beaufort Sea. In the Chukchi Sea, barrier chains generally had a larger area and temporal fluctuations were less severe. Larger, long-term increases in the area of barrier chain 34 is mostly attributed to a short-term increase in area between the 1950s and 1980s eras. Short-term changes and lack of data for the Chukchi Sea in the 2000s make it difficult to assume any longer term trends along that coast; however, the overall rate of area change is approximately one-third that of the change seen in the Beaufort Sea (table 4).

\section{Barrier Elevation}

Elevation data were extracted for the 2010s polygon boundaries from two sources: a 1 meter DEM derived from airborne lidar acquired between 2009 and 2012 between the United States-Canadian border to Icy Cape and a 1 meter DEM derived from SfM data acquired in 2016 from Icy Cape to Cape Beaufort (table 1). 
Barrier islands along the North Slope coast are generally low lying, with 75 percent of them having a maximum elevation of less than $3 \mathrm{~m}$. The highest barriers measured are located along the Chukchi Sea coast offshore of Point Lay $(8.1 \mathrm{~m})$ and near Icy Cape $(7.3 \mathrm{~m})$. Along the Beaufort Sea coast, the highest barriers include Flaxman Island, Eskimo Islands, and Cross Island, all of which reach more than $6 \mathrm{~m}$ high. The mean elevation of individual barriers is shown in figure 9 along with the distribution of mean barrier elevations along the Chukchi and Beaufort Sea coasts. Mean barrier elevation varied across the North Slope, with mean elevations predominantly less than 1 meter above sea level along the Beaufort Sea coast and elevations generally higher, between 1 and $2 \mathrm{~m}$ above sea level, along the Chukchi Sea coast.

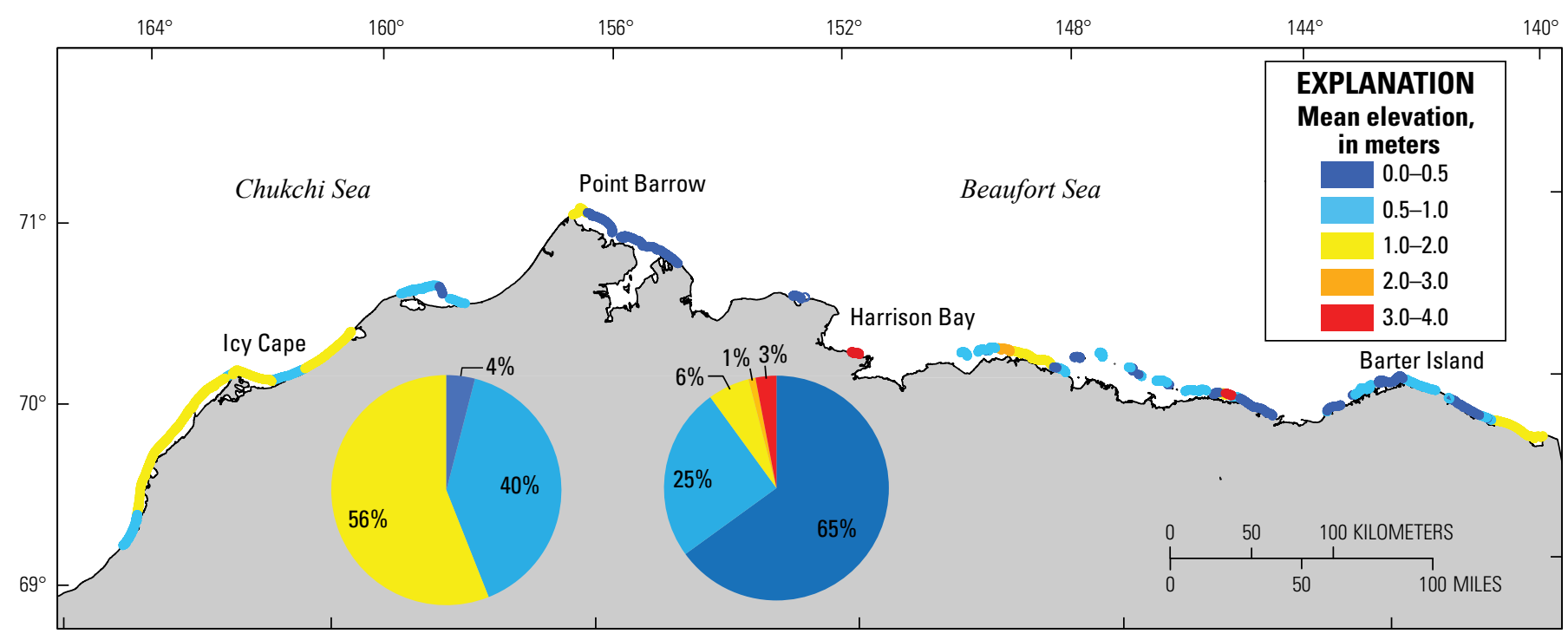

Figure 9. Map showing the mean elevation of barriers and the mean elevation distribution for Chukchi and Beaufort Sea coast barriers based on available light detection and ranging (lidar) and structure-from-motion (SfM) from the 2010s-era data. \%, percent; m, meter.

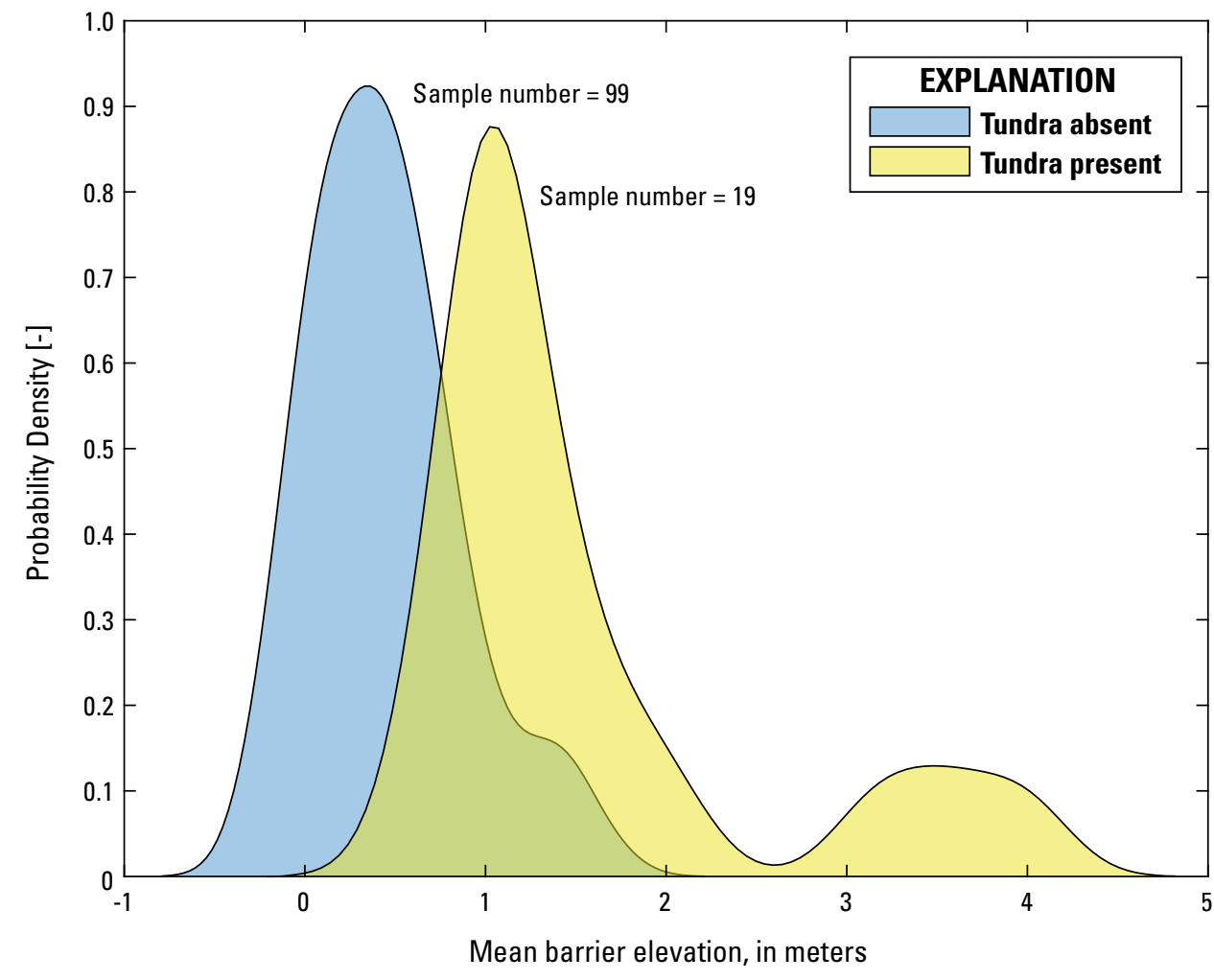

Figure 10. Plot of kernel probability density estimates of barrier elevations (in meters) with and without tundra vegetation present (based on 2010s data) for the study area in North Alaska.
Probability density estimates, using a kernel smoothing function, ${ }^{2}$ shows that the probability of higher elevations is greater in barrier chains with tundra present (fig. 10), and that the most likely elevation of barriers with tundra vegetation is approximately 0.8 meter higher than those without tundra vegetation $(0.3$ meter versus 1.1 meters above sea level).

\section{Barrier Width}

Boxplots showing the spatial and temporal distribution of barrier chain widths are presented in figure 11. Minimum, maximum, mean, and 25 th and 75 th percentile widths were also calculated but are

\footnotetext{
${ }^{2} \mathrm{~A}$ kernel distribution is a nonparametric representation of the probability density function (pdf) of a random variable. This distribution is defined by a smoothing function and a bandwidth value that controls the smoothness of the resulting density curve. Similar to a histogram, the kernel distribution builds a function to represent the probability distribution using the sample data. But unlike a histogram, which places the values into discrete bins, a kernel distribution sums the component smoothing functions for each data value to produce a smooth, continuous probability curve. Kernel distributions were calculated using MATLAB.
} 

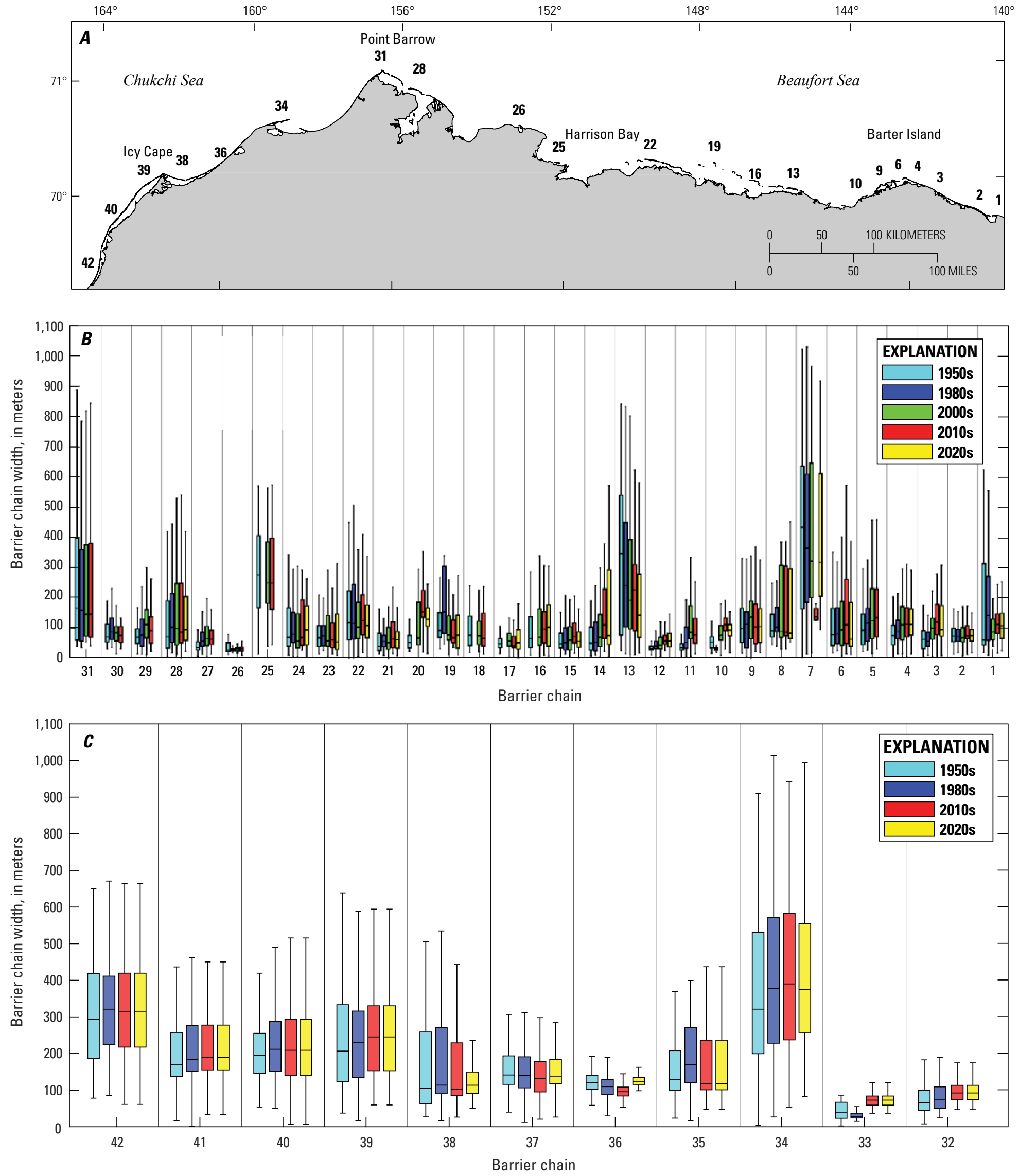

Figure 11. A, Map of barrier chains in the study area in North Alaska. Numbers show the barrier chains; numbers are assigned based on location from the east to west edges of the study area. Boxplots of barrier chain widths (in meters [m]) colored by era are shown for the Beaufort Sea $(B)$ and Chukchi Sea $(C)$ coasts. 
not shown. Average barrier widths over time range between 83 and $132 \mathrm{~m}$ (table 5). Additionally, the average widths of barriers in the study area have increased over time, which corresponds with the increase in area presented above. Average barrier width is generally greater in the Chukchi Sea, and while barrier widths do vary over time, they remain relatively stable over the long term (fig. 11). Barrier chains 7 and 13, for example, experienced notable decreases in mean width between the 1950s and 1980s eras. A kernel distribution (fig. 12) also shows that width is related to the presence of tundra, and barriers with tundra vegetation tend to be wider.
Table 5. Mean widths (in meters) of barriers in the study area over time.

\begin{tabular}{lrrccc}
\hline \multicolumn{1}{c}{ Region } & 1950s & 1980s & 2000s & 2010s & 2020s \\
\hline Entire study area & 83.3 & 103.8 & NA & 132.1 & 116.8 \\
Beaufort Sea & 73.7 & 86.0 & 90.6 & 116.7 & 114.3 \\
Chukchi Sea & 126.8 & 181.3 & NA & 187.9 & 137.5 \\
\hline
\end{tabular}

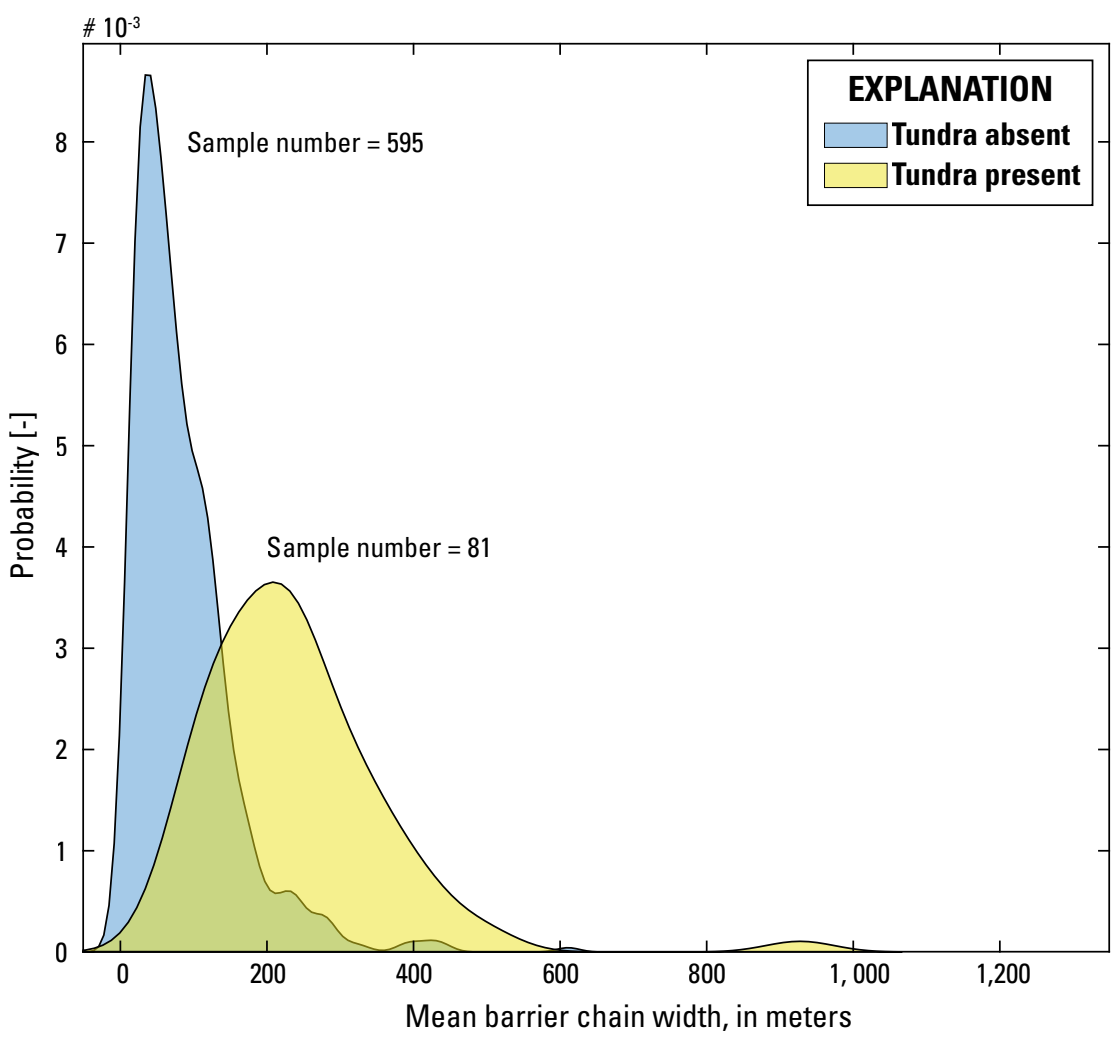

Figure 12. Plot of kernel probability density estimate of barrier chain width (in meters [m]) for barriers with and without tundra vegetation present.

\section{Barrier Sinuosity}

The sinuosity of barriers is shown to be stable in the long term yet fluctuate in the short-term (between eras). A boxplot of barrier chain sinuosity for the different analysis areas shows this trend, and additionally highlights the difference in sinuosity of barriers along the Beaufort and Chukchi Sea coastlines (fig. 13). Barriers are slightly less sinuous on the Chukchi Sea coast and show less variation through time than those along the Beaufort Sea coast. Sinuosity is highest between barrier chains 13 and 25 along the central Beaufort Sea coast where barriers are more arcuate. The kernel probability density estimate indicates that sinuosity values close to 1.0 are probable for both barriers with and without tundra present (fig. 14). Therefore, tundra presence is not a good indicator of sinuosity. However, no barriers in the study area with tundra vegetation had sinuosity levels greater than approximately 1.6. This correlation did not apply to barriers without tundra, some of which had sinuosity levels greater than 2 . 

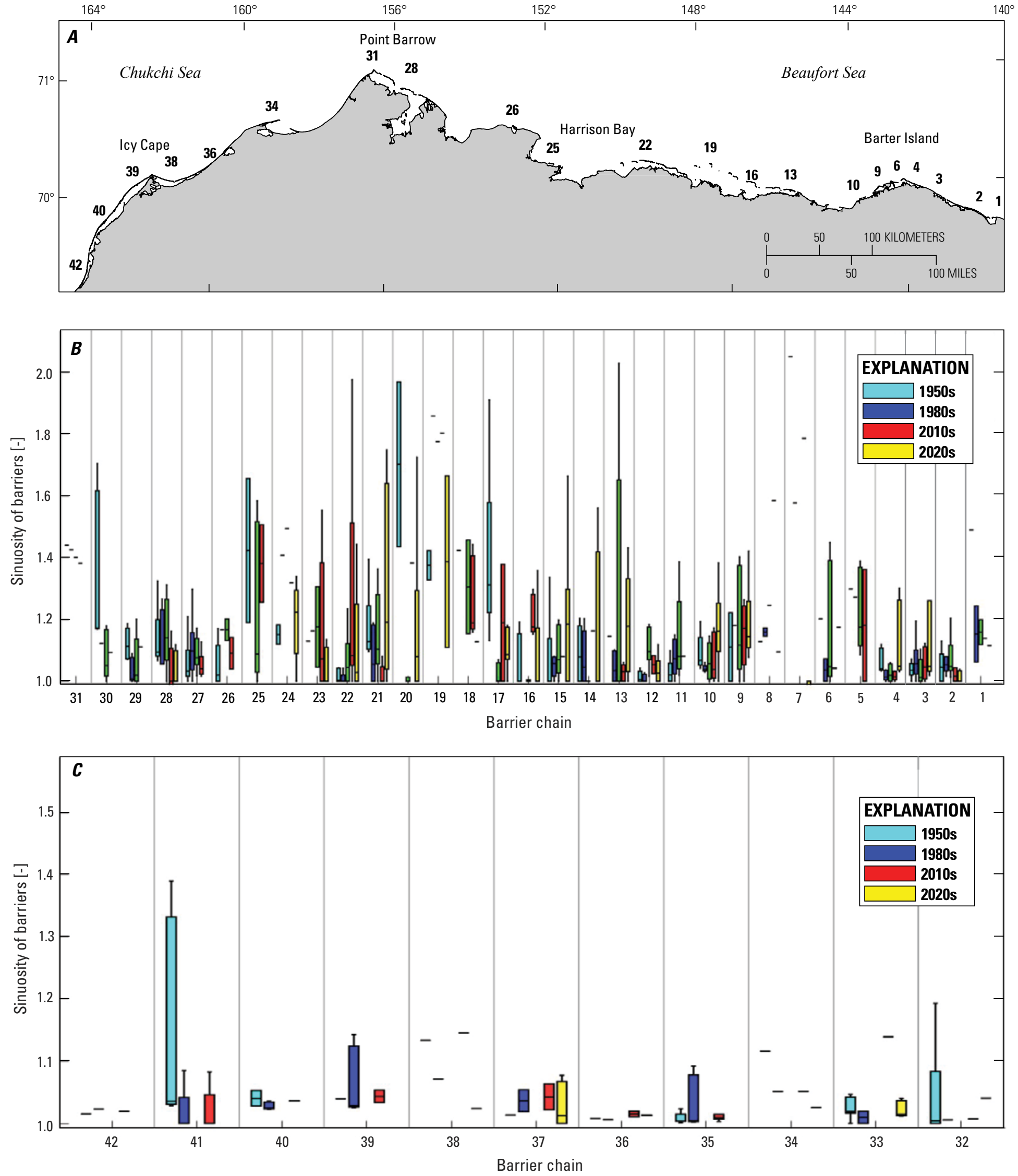

Figure 13. A, Map of barrier chains in the study area in North Alaska. Numbers show the barrier chains; numbers are assigned based on location from the east to west edges of the study area. Boxplots of barrier chain sinuosity over time along the Beaufort Sea $(B)$ and Chukchi Sea $(C)$ coast. Chains with less than three islands are presented as single data points. Chains with fewer than three barriers are presented as a single data point. 


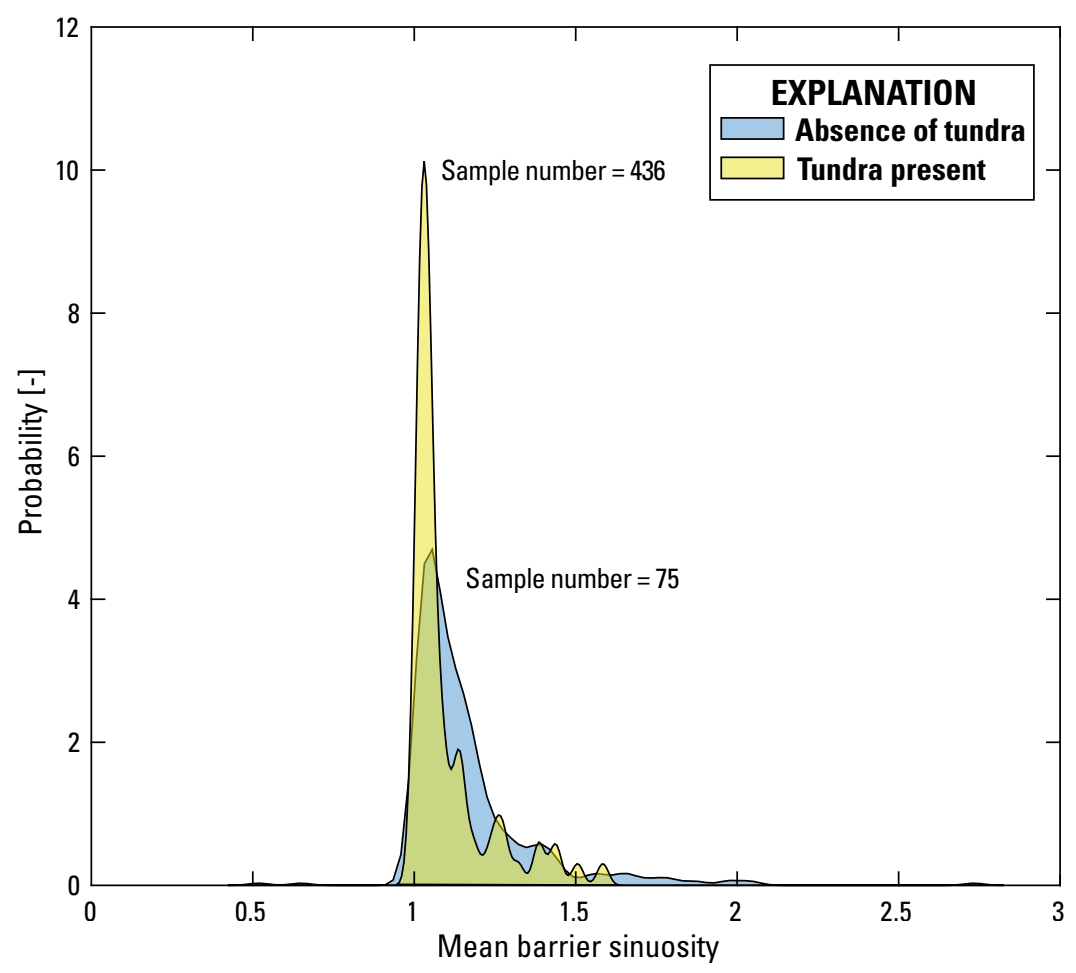

Figure 14. Plot of kernel probability density estimate of sinuosity for barriers with and without tundra vegetation present.

\section{Recurved Features and Relict Termini}

It is of interest to test the relation between recurved features and the presence of relict termini because of the apparent overlap in their formation. Both features are products of changing wind and wave conditions, as well as sediment availability. The presence of recurved barriers and number of relict termini on barriers varied widely over the study period, highlighting the dynamic nature of these features (figs. 15 and 16, respectively). Most barriers along the North Slope do not have recurved features on either terminus, but when present, it is generally most common that they exist on both ends. When only present on one end, relict termini were more common on the eastern terminus of barriers, though some exceptions do exist, for instance in the 1950s along the Chukchi Sea coast and in the 1980s along the Beaufort Sea coast (fig 15). Between the 1950s and 2010s eras, the number of recurved barriers increased. Most of this increase occurred on barriers in the Chukchi Sea, although there are relatively few recurved barriers along the Chukchi Sea coast compared to the Beaufort Sea coast. Relict termini were more common features on the eastern terminus of barriers on the Beaufort Sea coast whereas fluctuations between eras show no clear trend for barriers in the Chukchi Sea (fig. 16).

A recurved barrier was shown to be a poor predictor of the presence of relict termini on both the western $\left(R^{2}=0.54\right)$ and eastern $\left(R^{2}=0.55\right)$ terminus of barriers along the Beaufort Sea.
In the Chukchi Sea, a recurved barrier terminus was not a good predictor of relict termini on the eastern end $\left(R^{2}=0.12\right)$, but a good predictor $\left(R^{2}>0.6\right)$ variable for relict termini on the western end of barriers $\left(R^{2}=0.65\right)$. Still, a recurved barrier does not necessarily indicate the presence of relict termini as the results pose a notable level of uncertainty.

\section{Barrier Orientation}

Barrier orientation data are presented as a cardinal angle (in degrees) for which the median barrier chain shoreline orientation is represented by the angle vector. Barrier chains with a median orientation of 90 or 270 degrees would therefore have a shoreline running straight from east to west (further clarified in fig. 17). The average orientation of barriers is between 145 and 162 degrees across the study area, and most barriers trend parallel to the mainland coast. Chains along the Beaufort Sea coast have smaller orientation values, below 160 degrees (from northwest to southeast) whereas barriers in the Chukchi Sea have greater orientation values (above 180 degrees, or southwest to northeast; table 6). Over time, mean barrier orientation values along the entire North Slope have become larger, indicating a clockwise shift in barrier orientation. This shift occurred primarily along the Beaufort Sea coast where barriers are increasingly oriented to the southwest (fig. 17). 

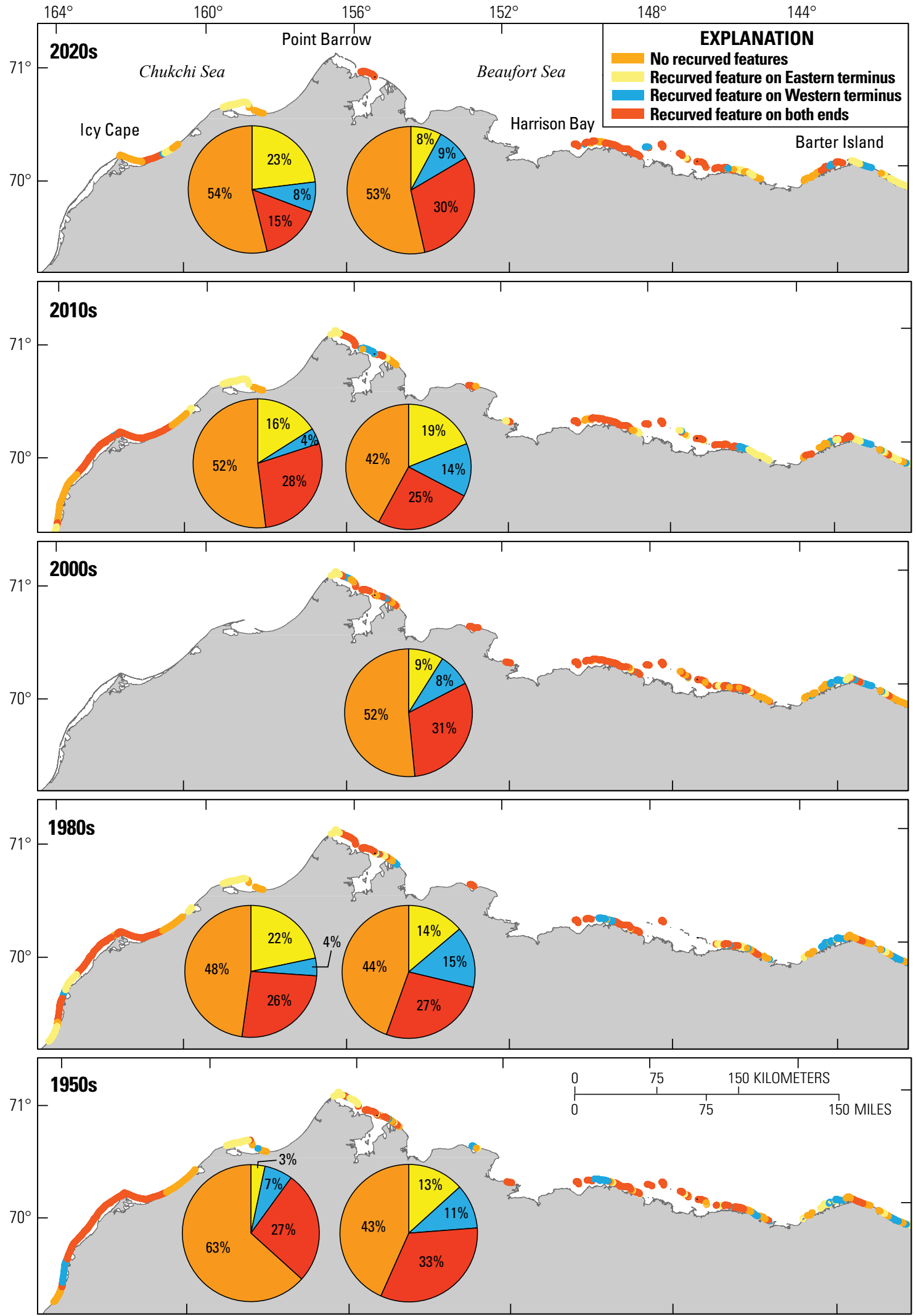

Figure 15. Maps of the North Alaska study area showing the presence of recurved features on barriers along both the Chukchi and Beaufort Sea coasts for the five analysis eras. \%, percent. 

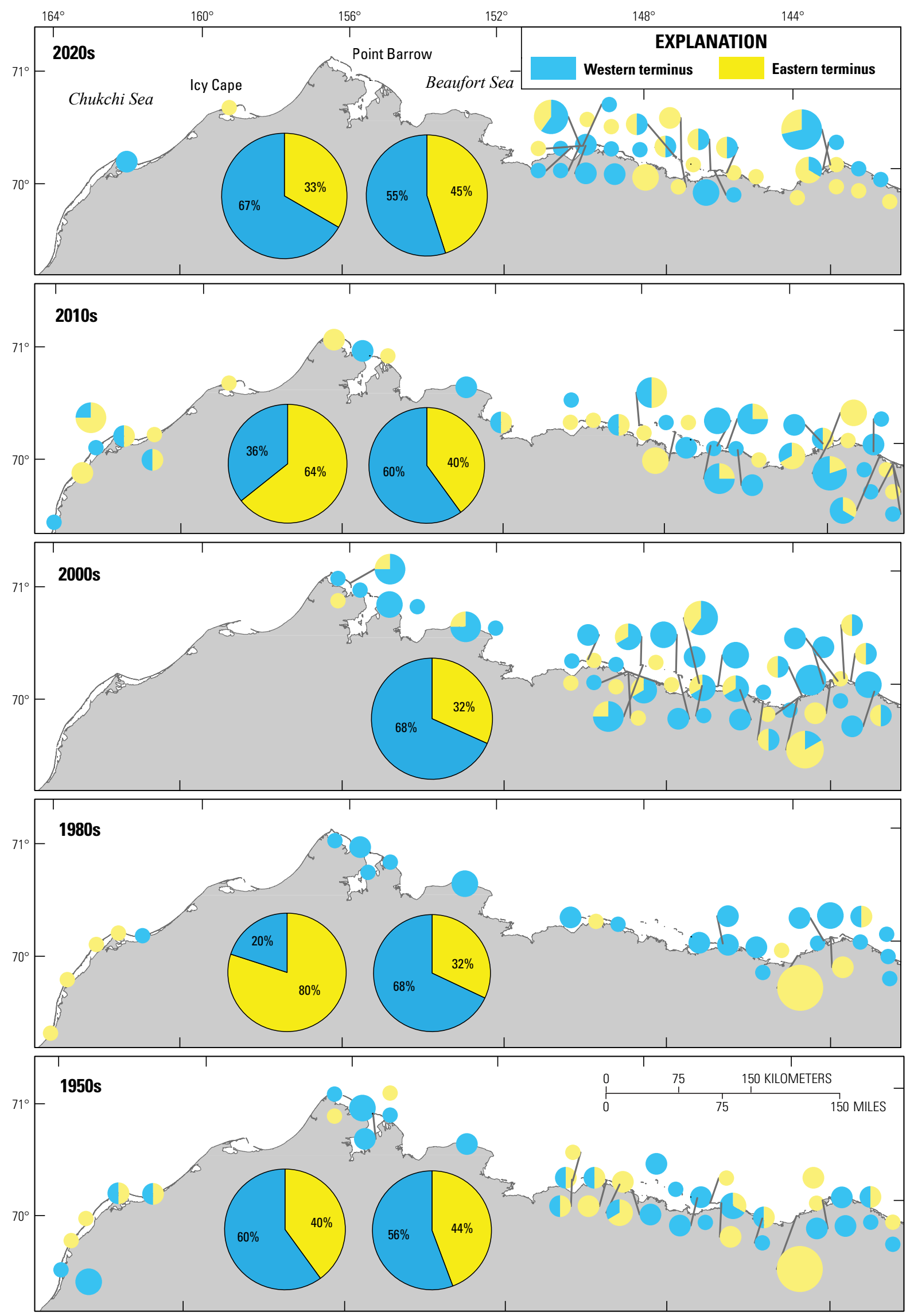

Figure 16. Maps of the North Alaska study area showing the presence of relict termini on western and eastern barrier termini along both the Chukchi and Beaufort Sea coasts for the five analysis eras. \%, percent. 


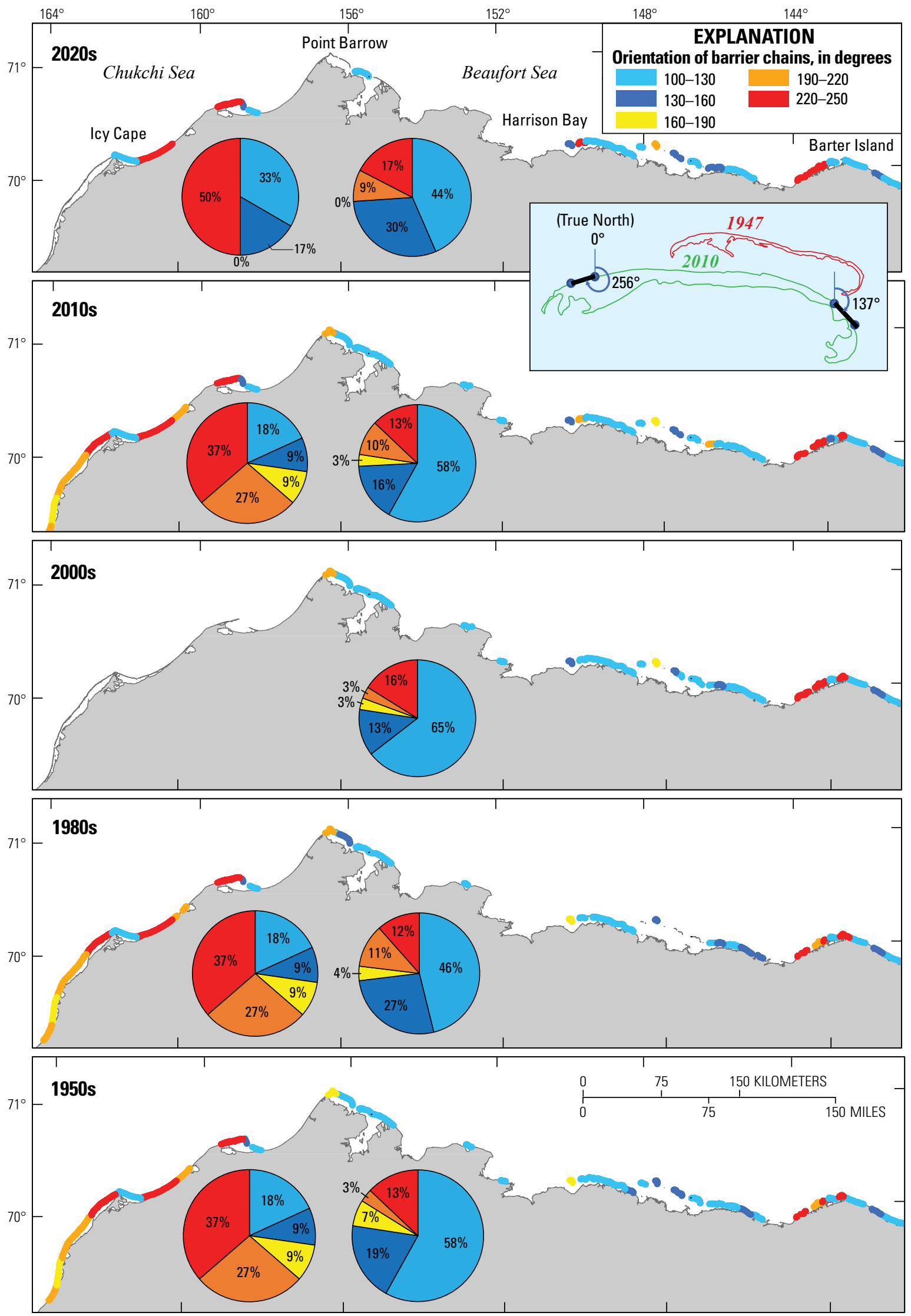

Figure 17. Maps of the North Alaska study area showing orientation of barrier chains in cardinal degrees along the Beaufort Sea (right) and Chukchi Sea (left) coasts for the five analysis eras. The inset shows a visual example of changing barrier orientation. \%, percent. 
Table 6. Mean and range of orientation (in degrees) of barriers in the North Alaska study area for the five analysis eras.

\begin{tabular}{lrrrrr}
\hline \multicolumn{1}{c}{ Region } & 1950s & 1980s & 2000s & 2010s & 2020s \\
\hline Mean orientation \\
\hline Entire study area & 156.6 & 161.7 & 145.2 & 159.5 & 158.9 \\
Beaufort Sea & 144.0 & 149.4 & 145.2 & 148.0 & 153.2 \\
Chukchi Sea & 191.8 & 190.8 & NA & 192.0 & 180.6 \\
\hline \multicolumn{7}{c}{ Orientation range } \\
\hline Entire study area & 145.0 & 143.2 & NA & 143.4 & 144.4 \\
Beaufort Sea & 143.2 & 129.6 & 133.0 & 135.8 & 126.8 \\
Chukchi Sea & 142.6 & 143.2 & NA & 143.4 & 144.4 \\
\hline
\end{tabular}

\section{Wave Climate and Barrier Orientation}

Wave heights, incident directions, and their probability of occurrence across the study area are summarized in decadal wave rose diagrams in figure 18, and further detailed in appendix 3 . Wave data are only available from 1979, so earlier data are not presented. Figure 18 also shows the median value of barrier island outer coast azimuths (orientations) within each barrier chain.

Most waves approach from the east to northeast. Results show the direction of incoming waves has changed over time, and waves reaching significant wave height approach from a wider range of directions (fig. 18). Mean significant wave heights are slightly smaller in the central Beaufort Sea, and both wave height and mean wave period (not shown) have increased since the 1980s era. In the Beaufort Sea, an easterly shift in wave direction coincides with a similar shift in barrier orientation. This is not as clear along the Chukchi Sea coast where fewer data are available and fewer changes are seen in barrier orientation.

\section{Summary}

This report summarizes changes to barrier morphology in time and space along the North Slope of Alaska between the United States-Canadian border and Cape Beaufort from 1947 to 2020 . Overall, there has been a decrease in the total number of barriers - although some barrier chains have also experienced increases in number of barriers - and an increase in barrier chain area since 1947. Barriers in the Chukchi Sea were found to have a greater area, width, and elevation than those in the Beaufort Sea, and these morphometrics were more stable over time in the Chukchi Sea. Tundra presence was found to be a good indicator for greater mean barrier chain widths (greater than $200 \mathrm{~m}$ ) and higher mean barrier chain elevations (greater than 1 meter). Though tundra vegetation certainly helps stabilize these barriers, whether it is the relative geologic stability allowing for greater vegetation density or the presence of tundra vegetation that is stabilizing the barriers is still unclear. The mean sinuosity of barrier chains in the Beaufort Sea is higher, reflecting more mobile features associated with constructed barriers, and though tundra vegetation does not necessarily determine lower sinuosity values, absence of tundra is associated with barriers of greater sinuosity (greater than 1.6).

Barriers are simultaneously becoming wider and shifting clockwise in the Beaufort Sea. Changing wave climate along the Beaufort and Chukchi Sea coasts may help explain changes to barrier orientation and may also have a considerable effect on the number of barrier islands, number and presence of relict termini, and barrier recurvature. Further analysis of climate indices and local wave conditions are still needed to assess these effects. Variations in total number of barriers may be caused by changing levels of sediment supply, and (or) perhaps caused by changing wave climate that can cause local instances of island division owing to storm breaching and flooding.

Barriers are more often recurved on both ends rather than on just one. Fewer barriers are recurved now compared to the 1950s era, which may be because of the addition of new barriers that have not yet been recurved by wind and waves. Relict termini that have been overtaken by a new terminus are more numerous on the western ends of barriers. Changing wave climate in both the Beaufort and Chukchi Seas may also help explain the recurvature of barriers and the presence of relict termini. As waves become more easterly in the Beaufort Sea, the diffraction of waves on the eastern end of barriers could help recurve the barriers and form new termini over time. Recurvature of barriers was shown to be a poor predictor for the presence of relict termini. As wave heights increase over time, and wave directions become increasingly easterly, barrier orientations are shifting clockwise along the Beaufort Sea coast whereas this is less clear in the Chukchi Sea where barrier orientation and number of barriers have been more stable over time.

Figure 18. Maps of the North Alaska study area showing wave conditions at points along the Chukchi and Beaufort Sea coasts as well as mean barrier chain orientation for the 2020s, 2010s, 2000s, and 1980s eras. Numbers represent ERA5 wave grid points and are numbered from west to east. Rose diagrams show cardinal directions in degrees. m, meter; ERA5, fifth generation of the European Centre for Medium-range Weather Forecasts. 

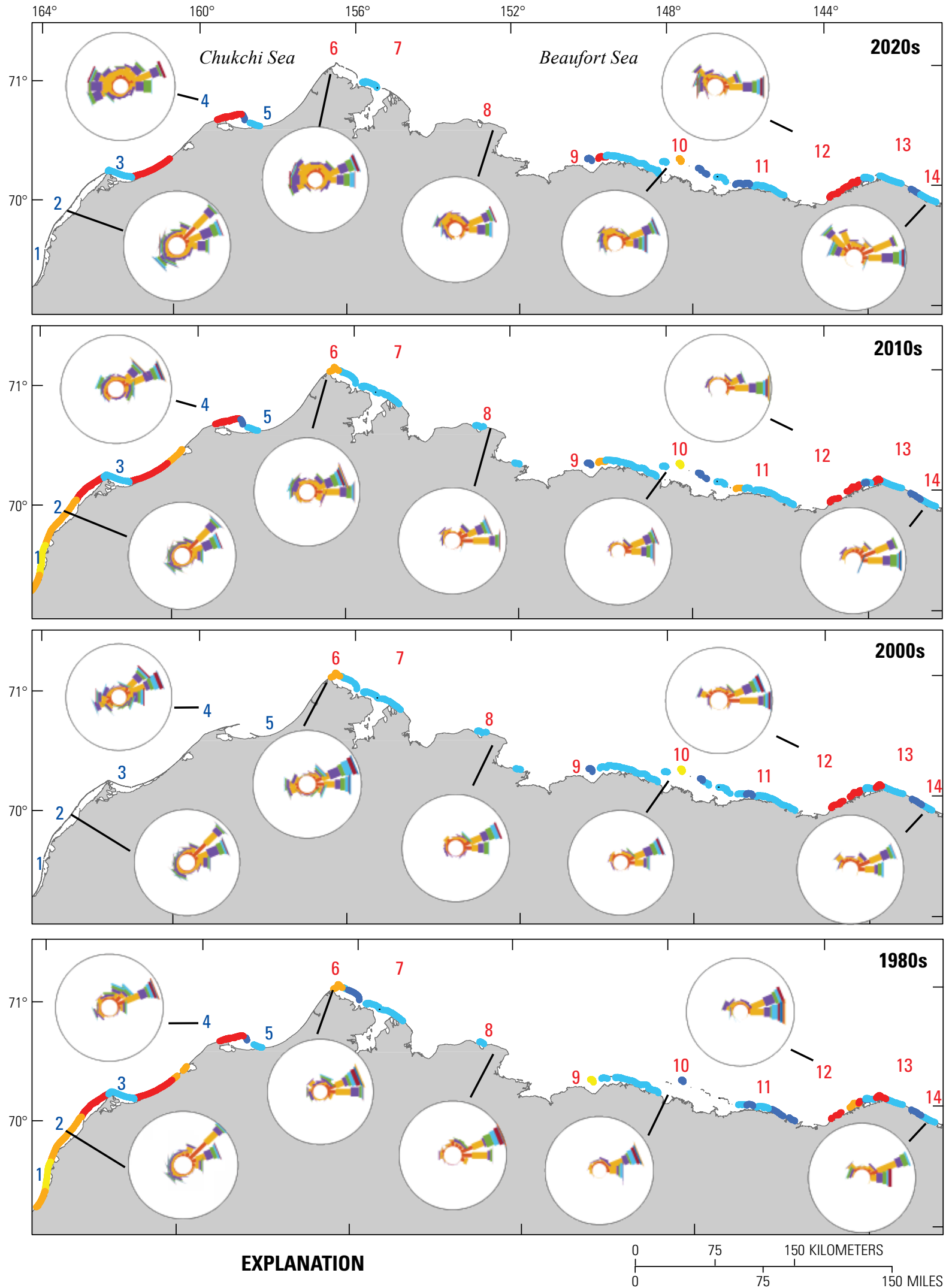

Signature wave height, in meters

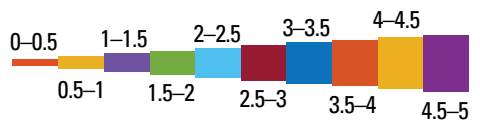

- Chukchi ERA5 Wave Grid Points

- Beaufort ERA5 Wave Grid Points
Orientation of barrier chains, in degrees

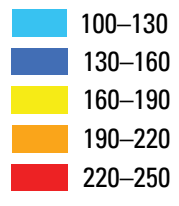




\section{References Cited}

Barnes, P.W., and Reimnitz, E., 1988, Construction of an arctic barrier island by alternating sea-ice pileup and overwash, in Galloway, J.P., and Hamilton, T.D., eds., Geologic studies in Alaska by the U.S. Geological Survey during 1987: U.S. Geological Survey Circular 1016, p. 180-182.

Barnhart, K.R., Overeem, I., and Anderson, R.S., 2014, The effect of changing sea ice on the physical vulnerability of Arctic coasts: The Cryosphere, v. 8, no. 5, p. 1777-1799, https://doi. org/10.5194/tc-8-1777-2014.

Delworth, T.L., Zeng, F., Vecchi, G.A., Yang, X., Zhang, L., and Zhang, R., 2016, The North Atlantic Oscillation as a driver of rapid climate change in the Northern Hemisphere: Nature Geoscience, v. 9, no. 7, p. 509-512, https://doi.org/10.1038/ ngeo 2738 .

Douglas, D.C., 2010, Arctic sea ice decline-Projected changes in timing and extent of sea ice in the Bering and Chukchi Seas: U.S. Geological Survey Open-File Report 2010-1176, 32 p., https://pubs.usgs.gov/of/2010/1176.

Eicken, H., Gradinger, R., Gaylord, A., Mahoney, A., Rigor, I., and Melling, H., 2005, Sediment transport by sea ice in the Chukchi and Beaufort Seas - Increasing importance due to changing ice conditions?: Deep Sea Research Part II-Topical Studies in Oceanography, v. 52, no. 24-26, p. 3281-3302, https://doi. org/10.1016/j.dsr2.2005.10.006.

Gibbs, A.E., Nolan, M., Richmond, B.M., Alexander G.S., and Li, H.E., 2019, Assessing patterns of annual change to permafrost bluffs along the North Slope coast of Alaska using high-resolution imagery and elevation models: Geomorphology, v. 336, p. 152-164, https://doi.org/10.1016/j.geomorph.2019.03.029.

Gibbs, A.E., and Richmond, B.M., 2015, National assessment of shoreline change-Historical shoreline change along the north coast of Alaska, U.S.-Canadian border to Icy Cape: U.S. Geological Survey Open-File Report 2015-1048, 96 p., https:// doi.org/10.3133/ofr20151048.

Gibbs, A.E., and Richmond, B.M., 2017, National assessment of shoreline change-Summary statistics for updated vector shorelines and associated shoreline change data for the north coast of Alaska, U.S.-Canadian border to Icy Cape: U.S. Geological Survey Open-File Report 2017-1107, 21 p., https:// doi.org/10.3133/ofr20171107.

Gibbs, A.E., Ohman, K.A., Coppersmith, R., and Richmond, B.M., 2017, A GIS compilation of updated vector shorelines and associated shoreline change data for the north coast of Alaska, U.S. Canadian Border to Icy Cape: U.S. Geological Survey data release, https://doi.org/10.5066/F72Z13N1

Gibbs, A.E., Snyder, A.G., and Richmond, B.M., 2019, National assessment of shoreline change-Historical shoreline change along the north coast of Alaska, Icy Cape to Cape Prince of Wales: U.S. Geological Survey Open-File Report 2019-1146, 52 p., https://doi.org/10.3133/ofr20191146.
Hamilton, A.I., Gibbs, A.E., Erikson, L.H., and Engelstad, A.C., 2021, Historical shorelines and morphological metrics for barrier islands and spits along the north coast of Alaska between Cape Beaufort and the U.S.-Canadian border, 1947 to 2019: U.S. Geological Survey data release, https://doi.org/10.5066/P90EQ1H7.

Hersbach, H., Bell, W., Berrisford, P., Horányi, A., Muñoz Sabater, J., Nicolas, J., Radu, R., Schepers, D., Simmons, A., Soci, C., and Dee, D., 2019, Global reanalysis - Goodbye ERA-Interim, hello ERA5: European Centre for Medium-Range Weather Forecasts Newletter, no. 159, https://doi.org/10.21957/vf291hehd7.

Himmelstoss, E.A., Henderson, R.E., Kratzmann, M.G., and Farris, A.S., 2018, Digital Shoreline Analysis System (DSAS) version 5.0 user guide: U.S. Geological Survey Open-File Report 2018-1179, 110 p., https://doi.org/10.3133/ofr20181179.

Hopkins, D.M., and Hartz, R.W., 1978, Coastal morphology, Coastal erosion, and Barrier islands of the Beaufort Sea, Alaska: U.S. Geological Survey Open-File Report 1978-1063, 54 p., https://doi.org/10.3133/ofr781063.

Johnson, M., and Eicken, H., 2016, Estimating Arctic sea-ice freeze-up and break-up from the satellite record-A comparison of different approaches in the Chukchi and Beaufort Seas: Elementa-Science of the Anthropocene, v. 4, no. 000124. , https://doi.org/10.12952/journal.elementa.000124.

Jorgenson, M.T., and Brown, J., 2005, Classification of the Alaskan Beaufort Sea coast and estimation of carbon and sediment inputs from coastal erosion: Geo-Marine Letters, v. 25, no. 2/3, p. 69-80, https://doi.org/10.1007/s00367-004-0188-8.

Kashiwase, H., Ohshima, K.I., Nihashi, S., and Eicken, H., 2017, Evidence for ice-ocean albedo feedback in the Arctic Ocean shifting to a seasonal ice zone: Scientific Reports, v. 7, no. 8170, https://doi.org/10.1038/s41598-017-08467-z.

Kempema, E.W., Reimnetz, E., and Barnes, P.W., 1989, Sea ice sediment entrainment and rafting in the Arctic: Journal of Sedimentary Petrology, v. 59, no. 2, p. 308-317, http://dx.doi. org/10.1306/212F8F80-2B24-11D7-8648000102C1865D.

Lachenbruch, A.H., 1994, Permafrost, the active layer, and changing climate: U.S. Geological Survey Open-File Report 94-694, 43 p., Menlo Park, Ca.

Lachenbruch, A.H., and Marshall, B.V., 1986, Changing climateGeothermal evidence from permafrost in the Alaskan Arctic: Science, v. 234, no. 4777, p. 689-696., https://doi.org/10.1126/ science.234.4777.689.

Liu, J., Curry, J.A., and Hu, Y., 2004, Recent Arctic sea ice variability - Connections to the Arctic Oscillation and the ENSO: Geophysical Research Letters, v. 31, no. 9, https://doi. org/10.1029/2004GL019858.

Maslanik, J.A., Fowler, C., Stroeve, J., Drobot, S., Zwally, J., Yi, D., and Emery, W., 2007, A younger, thinner Arctic ice cover-Increased potential for rapid, extensive sea-ice loss: Geophysical Research Letters, v. 34, no. 24, https://doi. org/10.1029/2007GL032043. 
Morack, J.L., and Rogers, J.C., 1982, Marine seismic refraction measurements of near-shore subsea permafrost: Proceedings of the 4th Canadian Permafrost Conference, National Research Council of Canada, Calgary, Alberta, p. 249-255.

National Oceanic and Atmospheric Administration [NOAA], 2019, NOAA Shoreline Data Explorer, continually updated shoreline product: National Oceanic and Atmospheric Administration web site, accessed February 10, 2019, at https://www.ngs.noaa.gov/NSDE/.

National Oceanic and Atmospheric Administration [NOAA], 2020, Arctic Oscillation Index since January 1950: National Oceanic and Atmospheric Administration, National Weather Service, Climate Prediction Center web site, accessed April 7, 2020, at https://www.cpc.ncep.noaa.gov/products/ precip/CWlink/daily_ao_index/ao.shtml.

Onarheim, I.H., Eldevik, T., Smedsrud, L.H., and Stroeve, J.C., 2018, Seasonal and regional manifestation of Arctic sea ice loss: Journal of Climate, v. 31, no. 12, p. 4917-4932, https://doi.org/10.1175/JCLI-D-17-0427.1.

Osterkamp, T.E., and Romanovsky, V.E., 1999, Evidence for warming and thawing of discontinuous permafrost in Alaska: Permafrost and Periglacial Processes, v. 10, no. 1, p. 17-37, https://doi.org/10.1002/(SICI)10991530(199901/03)10:1<17::AID-PPP303>3.0.CO;2-4.

Petersen, D., Deigaard, R., Fredsøe, J., 2008, Modelling the morphology of sandy spits: Coastal Engineering, v. 55, p. 671-684. https://doi.org/10.1016/j.coastaleng.2007.11.009

Pithan, F., and Mauritsen, T., 2014, Arctic amplification dominated by temperature feedbacks in contemporary climate models: Nature Geoscience, v. 7, no. 3, p. 181-184, https://doi. org/10.1038/ngeo2071.

Ravens, T.M., and Lee, W.J., 2007, Evolution of a North Slope barrier Island (Narwhal Island, North Arctic Alaska), 19552007 [abs.]: American Geophysical Union, no. H34B-08.

Rigor, I.G., Wallace, J.M., and Colony, R.L., 2002, Response of sea ice to the Arctic Oscillation: Journal of Climate, v. 15 , no. 18 , p. 2648-2663, https://doi.org/10.1175/15200442(2002)015<2648:ROSITT>2.0.CO;2.

Ruz, M.H., Héquette, A., and Hill, P.R., 1992, A model of coastal evolution in a transgressed thermokarst topography, Canadian Beaufort Sea: Marine Geology, v. 106, no. 3-4, p. 251-278, https://doi.org/10.1016/0025-3227(92)90133-3.

Serreze, M.C., Box, J.E., Barry, R.G., and Walsh, J.E., 1993, Characteristics of Arctic synoptic activity: Meteorology and Atmospheric Physics, v. 51, p. 147-164.
Serreze, M.C., Lynch, A.H., Clark, M.P., 2001, The summer Arctic frontal zone as seen in the NCEP/NCAR reanalysis: Journal of Climate, v. 14, p. 1550-1567.

Shapiro Ledley, T., and Pfirman, S., 1997, The impact of sediment-laden snow and sea ice in the Arctic on climate: Climatic Change, v. 37, no. 4, p. 641-664, https://doi. org/10.1023/A:1005354912379.

Short, A.D., 1979, Barrier island development along the AlaskanYukon coastal plains: GSA Bulletin 90, p. 77-103. https://doi. org/10.1130/GSAB-P2-90-77

Snyder, A.G., and Gibbs, A.E., 2019, National assessment of shoreline change - A GIS compilation of updated vector shorelines and associated shoreline change data for the north coast of Alaska, Icy Cape to Cape Prince of Wales: U.S. Geological Survey data release, https://doi.org/10.5066/ P9H1S1PV.

Stuecker, M.F., Bitz, C.M., Armour, K.C., Proistosescu, C., Kang, S.M., Xie, S.P., Kim, D., McGregor, S., Zhang, W., Zhao, S., Cai, W., Dong, Y., and Jin, F.F., 2018, Polar amplification dominated by local forcing and feedbacks: Nature Climate Change, v. 8, no. 12, p. 1076-1081, https://doi.org/10.1038/ s41558-018-0339-y.

Stutz, M.L., and Pilkey, O.H., 2011, Open-ocean barrier islandsGlobal influence of climatic, oceanographic, and depositional settings: Journal of Coastal Research, v. 27, no. 2, p. 207-222, https://doi.org/10.2112/09-1190.1.

Thomson, J., and Rogers, W.E., 2014, Swell and sea in the emerging Arctic Ocean: Geophysical Research Letters, v. 41, no. 9, p. 3136-3140, https://doi.org/10.1002/2014GL059983.

Thomson, J., Fan, Y., Stammerjohn, S., Stopa, J., Rogers, W.E., Girard-Ardhuin, F., Ardhuin, F., Shen, Hayley, Perrie, W., Shen, Hui, Ackley, S., Babanin, A., Liu, Q., Guest, P., Maksym, T., Wadhams, P., Fairall, C., Persson, O., Doble, M., Graber, H., Lund, B., Squire, V., Gemmrich, J., Lehner, S., Holt, B., Meylan, M., Brozena, J., and Bidlot, J.R., 2016, Emerging trends in the sea state of the Beaufort and Chukchi seas: Ocean Modelling, v. 105, p. 1-12. https://doi.org/10.1016/j. ocemod.2016.02.009

Walker H.J., 1982, Arctic, coastal morphology, in Beaches and Coastal Geology, Encyclopedia of Earth Sciences Series: Springer, New York, NY, https://doi.org/10.1007/0-38730843-1_23.

Zhang, X., Walsh, J., Zhang, J., Bhatt, U., and Ikeda, M., 2004, Climatology and interannual variability of Arctic cyclone activity, 1948-2002: Journal of Climate, v. 17, p. 2300-2317. 
Appendixes 


\section{Appendix 1. Feature Type and Name or Geographic Area of Barrier Island Chains}

\begin{tabular}{|c|c|c|}
\hline $\begin{array}{c}\text { Barrier chain } \\
\text { number }\end{array}$ & Type & Name or geographic area \\
\hline 1 & Spit & Spit on the east side of Demarcation Bay \\
\hline 2 & Island(s) & West Demarcation Bay to Beaufort Lagoon (including Icy Reef) \\
\hline 3 & Spit & Beaufort Lagoon to Pokok Bay \\
\hline 4 & Mixed & Pokok Lagoon to Jago Spit \\
\hline 5 & Island(s) & Jago Spit \\
\hline 6 & Island(s) & Bernard Spit \\
\hline 7 & Spit & Spit on the east side of Barter Island \\
\hline 8 & Spit & Spit on the west side of Barter Island \\
\hline 9 & Island(s) & Arey Island to Hulahula River delta \\
\hline 10 & Island(s) & Hulahula River delta to Sadlerochit River (delta fronting barriers) \\
\hline 11 & Island(s) & Canning River delta \\
\hline 12 & Mixed & Canning River to Brownlow Point \\
\hline 13 & Island(s) & Flaxman Island \\
\hline 14 & Island(s) & Duchess Island \\
\hline 15 & Island(s) & Alaska and Challenge Islands \\
\hline 16 & Island(s) & Belvedere and Pole Islands \\
\hline 17 & Island(s) & Jeanette, Karluk, and McClure Islands \\
\hline 18 & Island(s) & Narwhal Island \\
\hline 19 & Island(s) & Cross and Bartlett Islands \\
\hline 20 & Island(s) & Argo, Reindeer, and Midway Islands \\
\hline 21 & Island(s) & Stump and Egg Islands \\
\hline 22 & Island(s) & Return, Long, Cottle, Bodfish, Bertoncini, Jones, Pingok, and Leavitt Islands \\
\hline 23 & Island(s) & Spy Islands \\
\hline 24 & Island(s) & Thetis Island \\
\hline 25 & Island(s) & Eskimo Islands \\
\hline 26 & Island(s) & Pogik Point \\
\hline 27 & Mixed & Sinclair River to Sanigaruak Pass and Tulimanik, Kulgurak, and Igalik Islands \\
\hline 28 & Island(s) & Sanigaruak Pass to Ekilukruak Entrance and Martin, Cooper, and Plover Islands \\
\hline 29 & Island(s) & Tapkaluk Islands \\
\hline 30 & Island(s) & Deadmans, Crescent, and Doctor Islands \\
\hline 31 & Spit & Point Barrow area \\
\hline 32 & Island(s) & Spit on the east side of Peard Bay \\
\hline 33 & Island(s) & Seahorse Islands \\
\hline 34 & Spit & Point Franklin \\
\hline 35 & Spit & Kuk River (Point Marsh) \\
\hline 36 & Island(s) & Kilmantavi to Pingorarok Pass \\
\hline 37 & Island(s) & Pingorarok Pass to Akoliakatat Pass \\
\hline 38 & Island(s) & Akoliakatat Pass to Icy Cape Pass \\
\hline 39 & Island(s) & Icy Cape Pass to Utukok Pass, Solivik Island \\
\hline 40 & Island(s) & Utukok Pass to Kukpowruk Pass \\
\hline 41 & Island(s) & Kukpowruk Pass to pass south of Naokok Pass \\
\hline 42 & Spit & Spit on the southwest side of Kasegaluk Lagoon \\
\hline
\end{tabular}




\section{Appendix 2. Total Barrier Chain Area}

[Values are in square meters. Dashes indicate chains where data are missing]

\begin{tabular}{|c|c|c|c|c|c|}
\hline Chain & 1950s & 1980s & $2000 s$ & 2010s & $2020 s$ \\
\hline 1 & 614,004 & 606,323 & 521,221 & 590,714 & 599,426 \\
\hline 2 & $3,972,480$ & $4,089,166$ & $4,061,283$ & $4,582,898$ & $4,190,377$ \\
\hline 3 & 627,358 & 690,045 & 918,235 & $1,196,195$ & 979,316 \\
\hline 4 & $1,798,156$ & $1,640,374$ & $2,292,587$ & $2,597,980$ & $2,528,217$ \\
\hline 5 & 618,629 & $1,360,947$ & $1,224,733$ & $1,253,803$ & - \\
\hline 6 & $1,093,969$ & $1,197,922$ & $1,164,428$ & $1,147,098$ & $1,006,747$ \\
\hline 7 & 532,149 & 489,053 & 521,115 & 503,376 & 506,128 \\
\hline 8 & 248,666 & 337,831 & 383,335 & 413,069 & 466,423 \\
\hline 9 & $1,261,700$ & $1,201,066$ & $1,266,256$ & $1,356,999$ & $1,470,100$ \\
\hline 10 & 226,384 & 182,740 & $1,095,951$ & $1,152,865$ & 850,162 \\
\hline 11 & 389,180 & 346,283 & $1,061,098$ & 972,116 & - \\
\hline 12 & 411,015 & 586,756 & 791,668 & $1,152,396$ & $1,141,283$ \\
\hline 13 & $3,289,936$ & $3,157,330$ & $2,911,683$ & $2,513,460$ & $2,416,967$ \\
\hline 14 & 329,195 & 581,607 & 661,325 & 784,425 & 924,209 \\
\hline 15 & 302,342 & 422,979 & 543,244 & 538,861 & 550,718 \\
\hline 16 & 780,297 & - & $1,015,810$ & 933,536 & 920,941 \\
\hline 17 & 268,460 & - & 189,940 & 85,391 & 393,921 \\
\hline 18 & 350,520 & - & 380,067 & 396,778 & 393,921 \\
\hline 19 & 540,533 & 650,777 & 634,995 & 637,643 & 492,472 \\
\hline 20 & 189,453 & - & 353,270 & 712,250 & 500,631 \\
\hline 21 & 407,004 & 553,615 & 629,052 & 777,336 & 935,356 \\
\hline 22 & $7,162,169$ & $6,286,686$ & $6,461,097$ & $7,329,176$ & $6,472,919$ \\
\hline 23 & 479,581 & 491,063 & 664,925 & 731,575 & 655,643 \\
\hline 24 & 523,843 & 594,635 & 531,329 & 626,671 & 597,791 \\
\hline 25 & $1,280,930$ & - & $1,178,729$ & $1,204,985$ & - \\
\hline 26 & 365,968 & 262,001 & 274,921 & 269,681 & - \\
\hline 27 & 959,064 & $1,440,875$ & $1,756,611$ & $1,487,602$ & - \\
\hline 28 & $1,778,170$ & $2,123,277$ & $2,154,346$ & $2,385,195$ & $2,263,963$ \\
\hline 29 & 997,421 & $1,369,716$ & $1,769,365$ & $1,674,406$ & - \\
\hline 30 & 188,148 & 276,916 & 335,024 & 300,835 & - \\
\hline 31 & $2,435,377$ & $2,387,394$ & $2,357,701$ & $2,354,406$ & - \\
\hline 32 & 740,002 & 749,123 & - & $1,097,260$ & $1,051,616$ \\
\hline 33 & 248,920 & 98,151 & - & 395,642 & 240,407 \\
\hline 34 & $8,485,879$ & $9,422,723$ & - & $9,803,130$ & $9,818,191$ \\
\hline 35 & $2,479,637$ & $2,156,909$ & - & $2,762,673$ & - \\
\hline 36 & $2,243,965$ & $1,989,521$ & - & $1,738,638$ & $1,963,976$ \\
\hline 37 & $3,214,741$ & $3,077,727$ & - & $3,137,307$ & $3,830,872$ \\
\hline 38 & $4,590,600$ & $4,952,838$ & - & $4,634,142$ & $3,671,638$ \\
\hline 39 & $7,584,862$ & $7,601,290$ & - & $8,073,099$ & - \\
\hline 40 & $11,044,963$ & $11,876,888$ & - & $11,888,089$ & - \\
\hline 41 & $5,509,368$ & $5,991,113$ & - & $13,645,177$ & - \\
\hline 42 & $5,043,792$ & $5,504,049$ & - & $5,558,807$ & - \\
\hline Total & $85,608,831$ & $86,747,708$ & $40,105,340$ & $105,397,684$ & $51,834,329$ \\
\hline
\end{tabular}




\section{Appendix 3. Wave Rose Diagrams for Each Era at Different Locations along Alaska's North Slope}

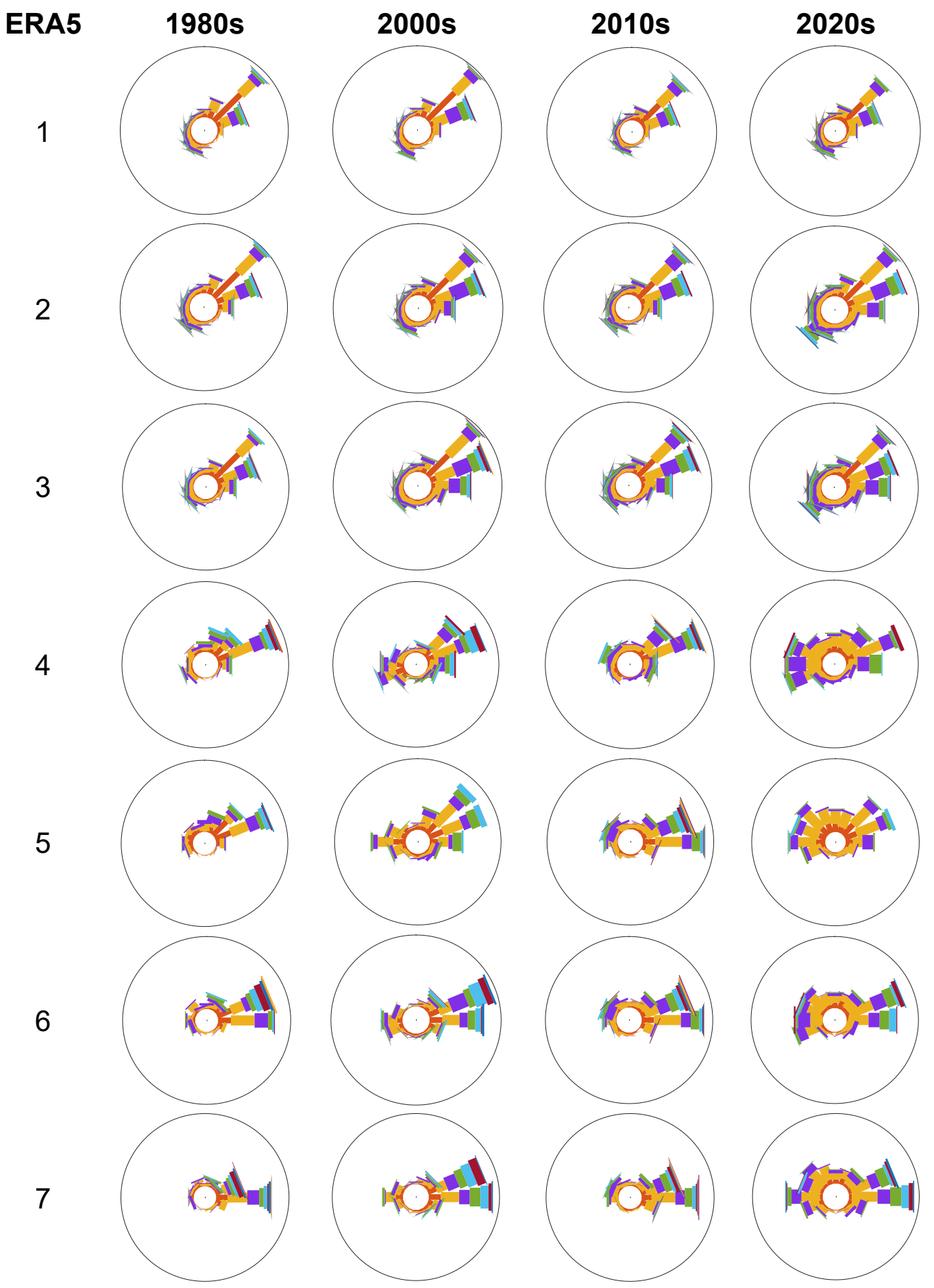

Figure 3.1. Rose diagrams of wave direction through time, shown in cardinal directions (in degrees). Waves are colored by height, in meters (m). ERA5, fifth generation of the European Centre for Medium-range Weather Forecasts. 


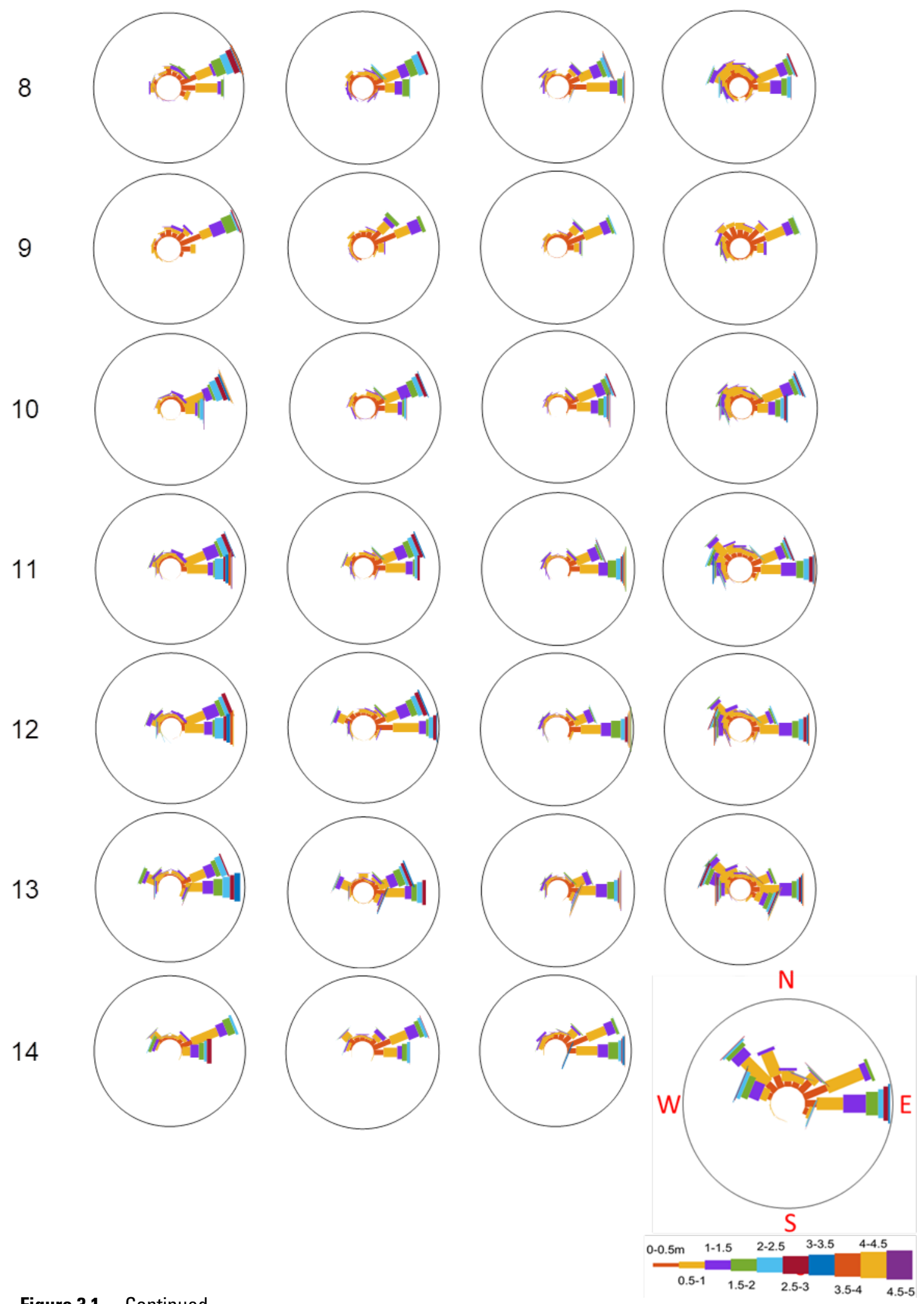

Figure 3.1.-Continued 
Moffett Field Publishing Service Center, California

Manuscript approved July 8, 2021

Edited by Mitchell Phillips

Layout by Cory Hurd 


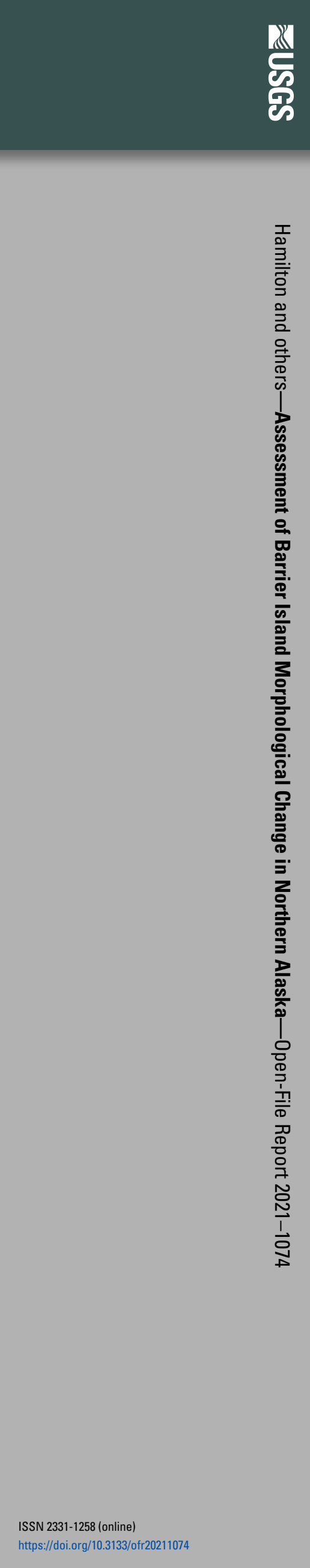

